\title{
Leaf cDNA-AFLP analysis of two citrus species differing in manganese tolerance in response to long-term manganese-toxicity
}

Chen-Ping Zhou ${ }^{1,2}$, Yi-Ping Qi ${ }^{3}$, Xiang You ${ }^{1,4}$, Lin-Tong Yang ${ }^{1,5}$, Peng Guo ${ }^{1}$, Xin Ye ${ }^{1,5}$, Xin-Xing Zhou ${ }^{1,5}$, Feng-Jiao Ke $\mathrm{K}^{1,5}$ and Li-Song Chen ${ }^{1,2,5^{*}}$

\begin{abstract}
Background: Very little is known about manganese (Mn)-toxicity-responsive genes in citrus plants. Seedlings of 'Xuegan' (Citrus sinensis) and 'Sour pummelo' (Citrus grandis) were irrigated for 17 weeks with nutrient solution containing $2 \mu \mathrm{M}$ (control) or $600 \mu \mathrm{M}$ (Mn-toxicity) $\mathrm{MnSO}_{4}$. The objectives of this study were to understand the mechanisms of citrus Mn-tolerance and to identify differentially expressed genes, which might be involved in Mn-tolerance.

Results: Under Mn-toxicity, the majority of $\mathrm{Mn}$ in seedlings was retained in the roots; C. sinensis seedlings accumulated more $\mathrm{Mn}$ in roots and less $\mathrm{Mn}$ in shoots (leaves) than C. grandis ones and Mn concentration was lower in Mn-toxicity C. sinensis leaves compared to Mn-toxicity C. grandis ones. Mn-toxicity affected C. grandis seedling growth, leaf $\mathrm{CO}_{2}$ assimilation, total soluble concentration, phosphorus $(\mathrm{P})$ and magenisum $(\mathrm{Mg})$ more than C. sinensis. Using CDNA-AFLP, we isolated 42 up-regulated and 80 down-regulated genes in Mn-toxicity C. grandis leaves. They were grouped into the following functional categories: biological regulation and signal transduction, carbohydrate and energy metabolism, nucleic acid metabolism, protein metabolism, lipid metabolism, cell wall metabolism, stress responses and cell transport. However, only 7 up-regulated and 8 down-regulated genes were identified in Mn-toxicity C. sinensis ones. The responses of C. grandis leaves to Mn-toxicity might include following several aspects: (1) accelerating leaf senescence; (2) activating the metabolic pathway related to ATPase synthesis and reducing power production; (3) decreasing cell transport; (4) inhibiting protein and nucleic acid metabolisms; (5) impairing the formation of cell wall; and (6) triggering multiple signal transduction pathways. We also identified many new Mn-toxicity-responsive genes involved in biological and signal transduction, carbohydrate and protein metabolisms, stress responses and cell transport.

Conclusions: Our results demonstrated that C. sinensis was more tolerant to Mn-toxicity than C. grandis, and that Mn-toxicity affected gene expression far less in C. sinensis leaves. This might be associated with more Mn accumulation in roots and less $\mathrm{Mn}$ accumulation in leaves of Mn-toxicity C. sinensis seedlings than those of $C$. grandis seedlings. Our findings increase our understanding of the molecular mechanisms involved in the responses of plants to Mn-toxicity.
\end{abstract}

Keywords: CDNA-AFLP, Citrus grandis, Citrus sinensis, Leaves, Manganese

\footnotetext{
*Correspondence: lisongchen2002@hotmail.com

'Institute of Horticultural Plant Physiology, Biochemistry and Molecular

Biology, Fujian Agriculture and Forestry University, 350002 Fuzhou, China

${ }^{2}$ College of Horticulture, Fujian Agriculture and Forestry University, 350002

Fuzhou, China

Full list of author information is available at the end of the article
} 


\section{Background}

Manganese (Mn), which is the twelfth abundant element and the third most common element in the Earth's crust, is absorbed mainly as $\mathrm{Mn}^{2+}$ by plant roots [1]. $\mathrm{Mn}$, an essential trace element for the normal growth and development of higher plant, is involved in many biochemical processes. With decreasing $\mathrm{pH}$, the amount of exchangeable $\mathrm{Mn}$ (mainly $\mathrm{Mn}^{2+}$ form) increases in the soil solution [2]. Like other heavy metals, however, $\mathrm{Mn}$ is harmful to most of the plants when present in excess [3,4]. After aluminum (Al), Mn-toxicity is probably the most important factor limiting plant productivity in acidic soils, which comprise up to $50 \%$ of the world's potentially arable lands [5]. Furthermore, the acidity of the soils is gradually increasing due to rapid industrialization, the emission of acidic gases and consequently acid deposition [6].

Disturbance of plant metabolism by Mn-toxicity happens in multiple ways. Toxic effects of Mn on plants include inhibition of growth, transpiration and photosynthesis [4,7-9], apoplastic deposition of oxidized Mn and phenolics [10,11], induction of oxidative stress through direct generation of reactive oxygen species (ROS) [3,12-16], interfering with the absorption, translocation, and use of other mineral elements $[4,15,17,18]$, impairment of leaf structure and chloroplast ultrastructure $[18,19]$, alteration of hormone balances $[18,20,21]$, modification of enzyme (i.e. ribulose-1,5-bisphosphate carboxylase/oxygenase [7,8], Mndependent superoxide dismutase [22], oxalate oxidase [23], indole-acetic acid oxidase [20], glycosy transferase [24], IAA-amino acid hydrolases [25], phenylalanine ammonialyase [26], phosphoenolpyruvate carboxykinase [27] and Mn-peroxidase [10]) activities, and affecting carbohydrate, amino acid, protein and nucleic acid metabolisms $[4,8,10,13,14,17,18,28]$.

To deal with heavy metal stresses, plants have evolved a considerable degree of developmental plasticity, including adaptive responses via cascades of molecular networks [29]. Increasing evidence shows that plant responses to heavy metal stresses is associated with changes in the expression profiles of genes involved in a broad spectrum of physiological, biochemical and cellular processes including carbohydrate and energy metabolism, photosynthesis, protein biosynthesis and degradation, nucleic acid metabolism, signal transduction, transcriptional regulation, cell transport and stress responses [30,31]. However, limited data are available on the differential expression of genes in response to Mn-toxicity in plants.

Techniques for gene expression analyses in plants have been widely explored. cDNA-amplified fragment length polymorphism (cDNA-AFLP), which does not require prior sequence information, is an efficient, sensitive, and reproducible technology for the discovery and identification of genes based on their polymorphism or differential expression patterns [32]. This technique is a robust and high-throughput tool for analysis of genome-wide gene expression fluctuation induced by a specific stress and is also a useful tool for the isolation of novel genes $[30,31,33]$.

Citrus belongs to evergreen subtropical fruit trees and is cultivated in humid and subhumid of tropical, subtropical, and temperate regions of the world mainly on acidic soils. Although the effects of Mn-toxicity on citrus chloroplast ultrastructure, $\mathrm{CO}_{2}$ assimilation, carbohydrates, photosynthetic electron transport and antioxidant systems have been investigated $[8,19]$, very little is known about $\mathrm{Mn}$ toxicity-responsive genes in citrus plants. In this study, we investigated the effects of Mn-toxicity on growth, leaf $\mathrm{CO}_{2}$ assimilation, leaf concentrations of malondialdehyde (MDA), chlorophyll (Chl) and total soluble protein, root, stem and leaf concentration of Mn, leaf phosphorus (P) and magnesium $(\mathrm{Mg})$ concentrations, and expression of leaf genes revealed by cDNA-AFLP in Citrus grandis and Citrus sinensis seedlings having different Mn-tolerance. The objectives of this study were to understand the mechanisms of citrus Mn-tolerance and to identify differentially expressed genes, which might be involved in Mn-tolerance.

\section{Results}

Plant growth, root, stem and leaf Mn concentration, and leaf $\mathrm{Mg}$ and $\mathrm{P}$ concentrations

For C. grandis, Mn-toxicity decreased root, shoot and whole plant (root + shoot) dry weight (DW), and increased the ratio of root DW to shoot DW. However, Mn-toxicity did not significantly affect root, shoot and whole plant DW in C. sinensis seedlings except for increased ratio of root DW to shoot DW. Root DW, whole plant DW and the ratio of root DW to shoot DW were higher in C. sinensis seedlings than in C. grandis ones or similar between two species, except that shoot DW was lower in the former at the $2 \mu \mathrm{M}$ Mn treatment (Figure 1). In addition, a few $C$. grandis leaves from the minority of Mn-toxicity plants became interveinal chlorosis or necrotic blotching of foliage, while no visible symptoms occurred in Mn-toxicity $C$. sinensis leaves (Additional file 1).

As shown in Figure 2, Mn-toxicity increased root, stem and leaf $\mathrm{Mn}$ concentration, $\mathrm{Mn}$ distribution in roots, $\mathrm{Mn}$ uptake per plant and per root DW, and decreased Mn distribution in stems and leaves. Under control condition, all these parameters did not significantly differ between $C$. grandis and C. sinensis seedlings. When exposed to Mntoxicity, stem Mn concentration, Mn uptake per plant and Mn distribution in roots were higher in C. sinensis seedlings than in C. grandis ones, while leaf Mn concentration and $\mathrm{Mn}$ distribution in leaves were lower in the former than in the latter.

Mn-toxicity decreased $\mathrm{P}$ and $\mathrm{Mg}$ concentrations in $C$. grandis leaves, but did not significantly affect them in $C$. sinensis leaves (Figure 3). 


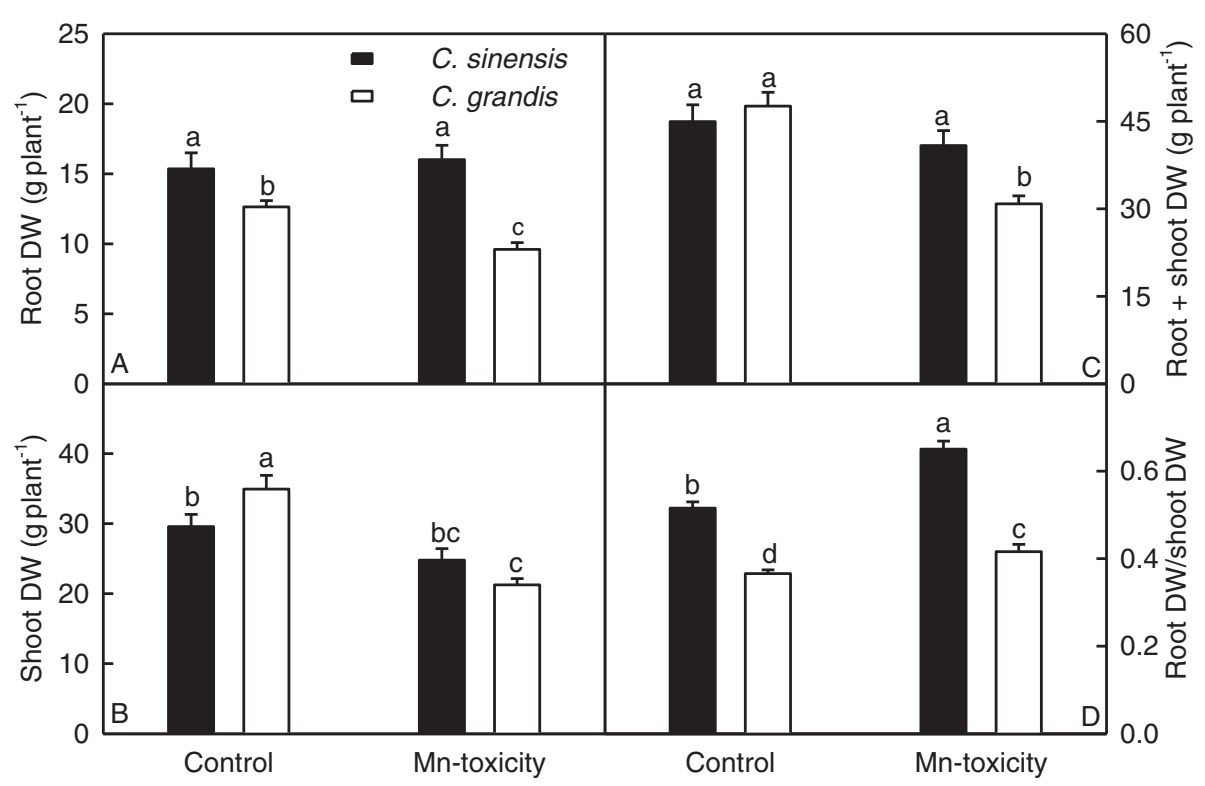

Figure 1 Effects of Mn-toxicity on growth of Citrus grandis and C. sinensis seedlings. (A-C) Root, shoot and root + shoot DW. (D) Ratio of root DW to shoot DW. Bars represent means \pm SE $(n=10)$. Different letters above the bars indicate a significant difference at $P<0.05$.

\section{Leaf total soluble protein, MDA and Chl concentrations} and gas exchange

Total soluble protein concentration was decreased by Mn-toxicity in C. grandis leaves, but was not significantly affected in C. sinensis ones (Figure 4A). As shown in Figure $4 \mathrm{~B}, \mathrm{Mn}$-toxicity did not significantly affect leaf concentration of MDA.

Mn-toxicity decreased $\mathrm{CO}_{2}$ assimilation (Figure 5A), transpiration (Figure 5B) and stomatal conductance (Figure 5C) in leaves of C. grandis and C. sinensis, especially in the former. Mn-toxicity increased intercellular $\mathrm{CO}_{2}$ concentration in $C$. grandis leaves, but did not significantly affect it in C. sinensis leaves (Figure 5D). Mntoxicity did not significantly affect leaf concentrations of $\mathrm{Chl} \mathrm{a}+\mathrm{b}, \mathrm{Chl} \mathrm{a}$ and $\mathrm{Chl} \mathrm{b}$, and the ratio of $\mathrm{Chl} \mathrm{a}$ to $\mathrm{Chl} \mathrm{b}$ in the two citrus species (Figure 5E-H).

\section{Identification of differentially expressed genes by cDNA-AFLP}

A total of 256 selective primer combinations were used for the cDNA-AFLP analysis in order to identify the genes responsive to Mn-toxicity in the leaves of two citrus species differing in $\mathrm{Mn}$-tolerance (Figure 6). For $C$. grandis leaves, a total of 16-37 (an average of 21.4) clear and unambiguous transcript-derived fragments (TDFs) were detected with each premier combination, which resulted in approximately 5490 TDFs, ranging from 100$750 \mathrm{bp}$. A total of 223 differentially expressed and reproducible TDFs were recovered from the silver-stained cDNA-AFLP gels based on their presence, absence or difference in the levels of expression. All these TDFs were re-amplified, ligated and sequenced, and 213 cDNA fragments produced useable sequence data. TDF sequences were compared with those present in the GenBank database (Additional file 2). Of the 213 TDF sequences, 99 TDFs showed significant homology to genes encoding known or putative proteins, and 23 TDFs were homologous to genes encoding uncharacterized proteins, hypothetical proteins or unknown proteins. The remaining 91 TDFs did not show homology to any nucleotide or amino sequence in the public databases. Of these 122 matched TDFs, 42 (34.4\%) TDFs increased and 80 (65.6\%) decreased in response to Mn-toxicity. According to the biological functional properties, these TDFs were classified into the following functional categories: biological regulation and signal transduction (18.9\%), carbohydrate and energy metabolism (10.7\%), nucleic acid metabolism (4.1\%), protein metabolism $(17.2 \%)$, lipid metabolism $(0.8 \%)$, cell wall metabolism (8.2\%), stress responses (10.7\%), cell transport (6.6\%), other and unknown biological processes (23.0\%) (Additional file 2, Figure 7B).

For C. sinensis leaves, a total of 16-37 (an average of 21.3) clear and unambiguous TDFs were obtained with each premier pair, which yield approximately 5450 TDFs, ranging from $100-750 \mathrm{bp}$. A total of 20 differentially expressed and reproducible TDFs were isolated from the silver-stained cDNA-AFLP gels. All these TDFs were sequenced, and produced readable sequences (Additional file 3). Of the 20 TDFs, 12 TDFs were homologous to genes encoding known or putative proteins, and three TDFs belonged to genes encoding hypothetical proteins. The remaining five TDFs had no database matches. 


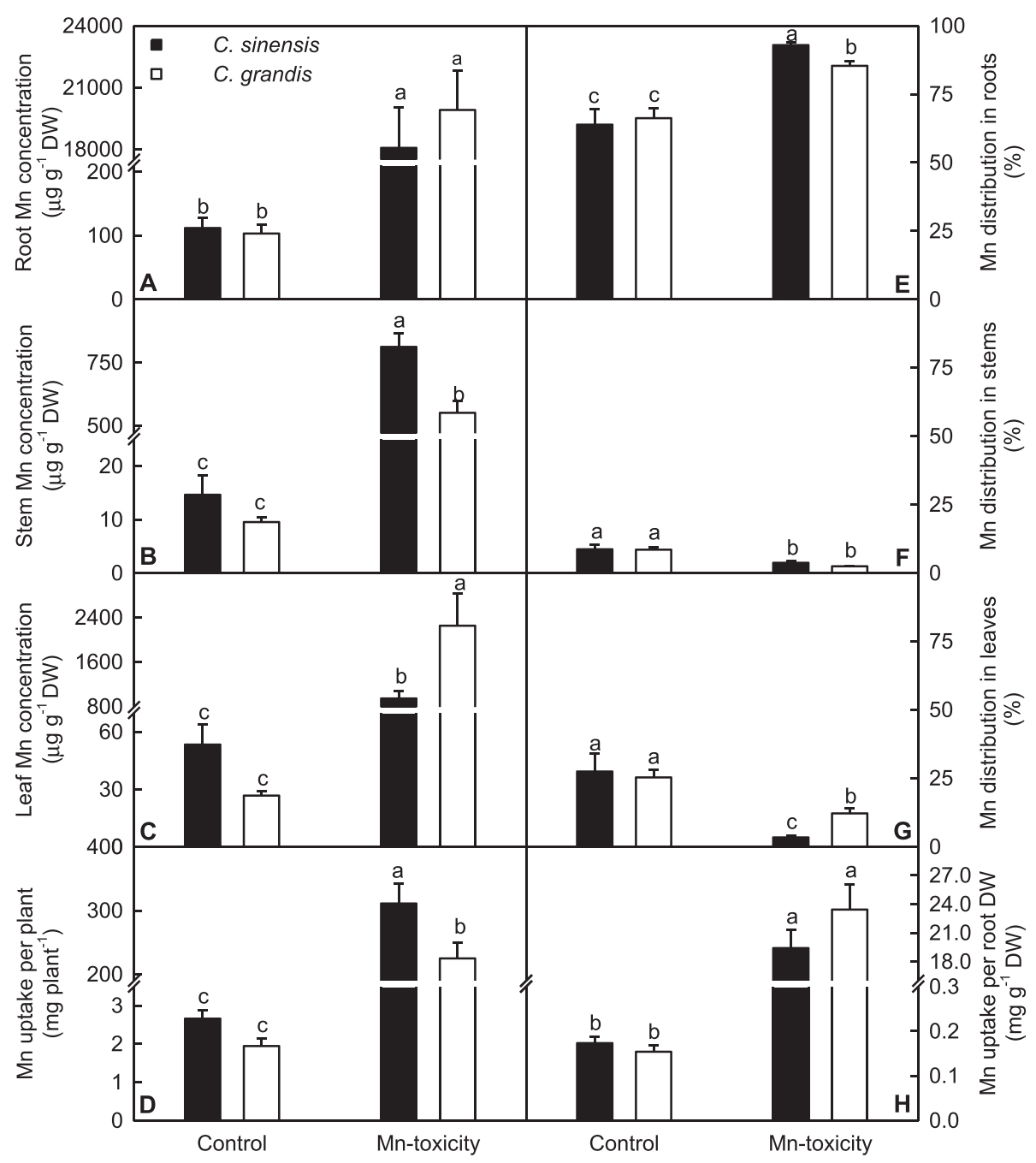

Figure 2 Effects of Mn-toxicity on root, stem and leaf Mn concentration, Mn uptake and Mn distribution. (A-C) Root, stem and leaf Mn concentration. (D) Mn uptake per plant. (E-G) Mn distribution in roots, stems and leaves. (H) Mn uptake per root DW. Bars represent means \pm SE $(n=4)$. Different letters above the bars indicate a significant difference at $P<0.05$.

Among the 15 matched TDFs, seven (46.7\%) TDFs were up-regulated and eight (53.3\%) was down-regulated by Mn-toxicity. These TDFs were involved in biological regulation and signal transduction (33.3\%), carbohydrate and energy metabolism (13.3\%), nucleic acid metabolism (13.3\%), protein metabolism $(6.7 \%)$, cell transport $(6.7 \%)$, other and unknown biological processes (26.7\%) (Additional file 3, Figure 7A).

qRT-PCR analysis of some Mn-toxicity-responsive genes To validate the cDNA-AFLP expression patterns, 15 TDFs from C. grandis leaves and one TDF from C. sinensis ones were selected for qRT-PCR analysis. The expression levels of all these TDFs except for two TDFs (TDFs \# 232-1 and 160-6) matched well with the expression profiles observed with cDNA-AFLP (Figure 8). The discrepancy in expression patterns for two TDFs between qRT-PCR and
cDNA-AFLP analysis might be due to gene family complexity. Nevertheless, the cDNA-AFLP technique allowed us to isolate the differentially expressed genes under $\mathrm{Mn}$ toxicity.

\section{Discussion}

C. sinensis is more tolerant to Mn-toxicity than C. grandis As shown in Figures 1 and $2 \mathrm{~A}-\mathrm{C}, 600 \mu \mathrm{M}$ Mn treatment greatly inhibited $C$. grandis plant growth, especially the shoots and increased the concentration of $\mathrm{Mn}$ in roots, stems and leaves, and foliar Mn concentration for $600 \mu \mathrm{M}$ $\mathrm{Mn}$ treatment was far more than the sufficiency range of 25-200 $\mathrm{mg} \mathrm{kg}^{-1}$ DW for sweet orange (C. sinensis) leaves [34]. Based on these results, plants that received $600 \mu \mathrm{M}$ $\mathrm{Mn}$ are considered Mn-excess (Mn-toxicity). Mn-toxicityinduced decrease in plant DW and increase in root DW/ shoot DW ratio (Figure 1) agree with the previous results 


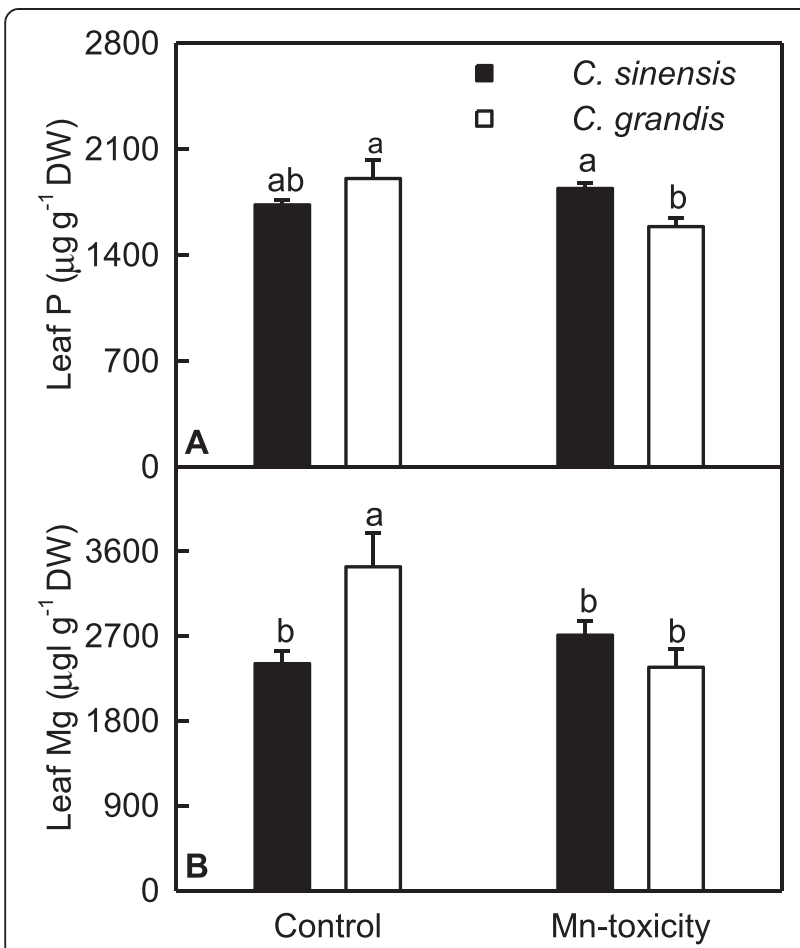

Figure 3 Effects of Mn-toxicity on $\mathrm{P}(\mathrm{A})$ and $\mathrm{Mg}(\mathrm{B})$ concentrations in leaves. Bars represent means \pm SE $(n=4)$. Different letters above the bars indicate a significant difference at $P<0.05$.

obtained on C. grandis [8] and with the view that Mntoxicity affects plant tops more than root systems [4]. Mntoxicity, however, had no influence on the ratio of root DW to shoot DW in lucerne (Medicago sativa) plants, despite Mn-toxicity depressed growth of shoots and roots [35].

Our results showed that $\mathrm{Mn}$-toxicity $C$. grandis plants had decreased root, shoot and root + shoot DW, and increased ratio of root DW to shoot DW, while Mn-toxicity did not significantly affect $C$. sinensis growth except for increased root DW/shoot DW ratio (Figure 1), meaning that C. sinensis is more tolerant to Mn-toxicity than C. grandis. This is also supported by our data that the gas exchange in $C$. grandis leaves was affected by Mn-toxicity far more than in C. sinensis ones (Figure 5A-D), and that Mntoxicity decreased total soluble protein, $\mathrm{P}$ and $\mathrm{Mg}$ concentrations only in C. grandis leaves (Figures 3 and 4A). Like that of previous workers $[8,36,37]$, the observed lower $\mathrm{CO}_{2}$ assimilation in Mn-toxicity leaves of C. grandis and $C$. sinensis was primarily caused by non-stomatal factors because the decreases in both $\mathrm{CO}_{2}$ assimilation and stomatal conductance was accompanied by unchanged or increased intercellular $\mathrm{CO}_{2}$ assimilation (Figure 5A, C and D). It is noteworthy that the reduction in $\mathrm{CO}_{2}$ assimilation in leaves of Mn-toxicity plants could not attributed to photo-oxidative damage and decreased Chl, because there were no significant differences in leaf concentrations of MDA (a marker of peroxidative damage), Chl a+b, Chl a

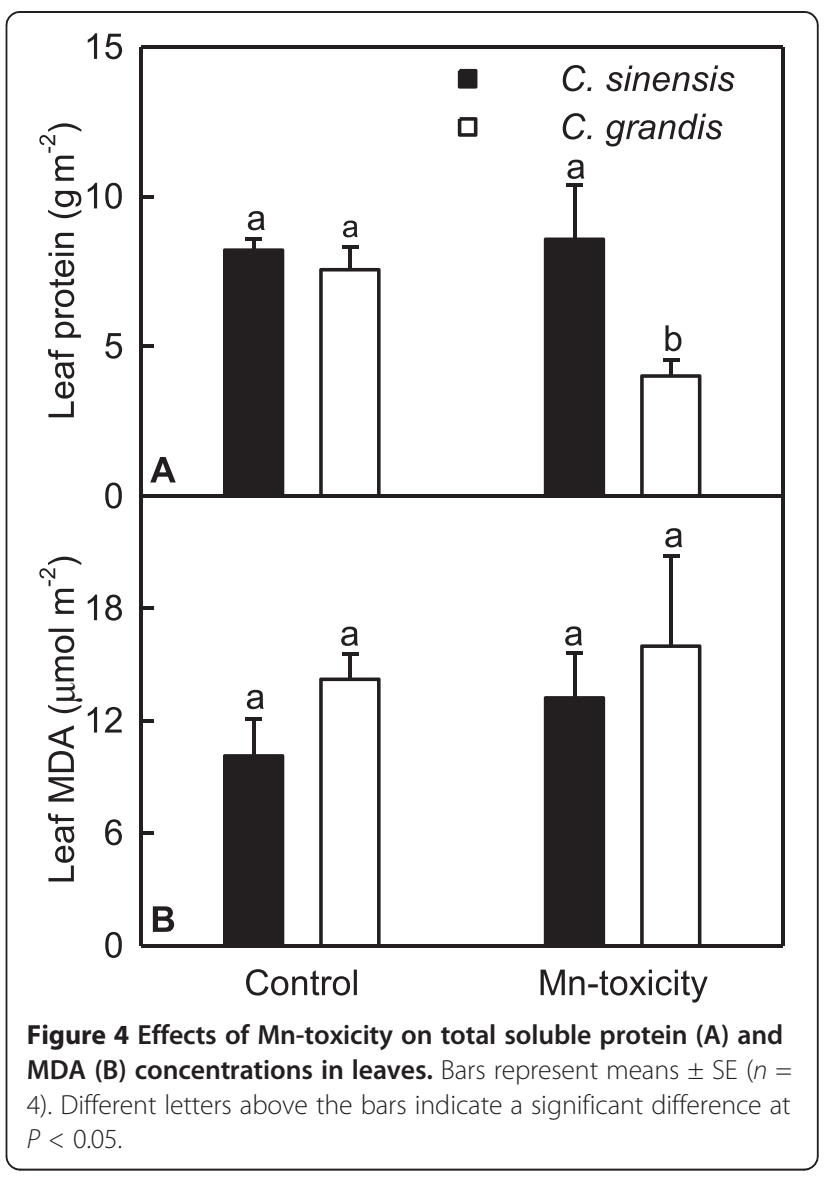

and $\mathrm{Chl} b$ (Figures $4 \mathrm{~B}$ and $5 \mathrm{E}-\mathrm{G}$ ) between control and Mn-toxicity leaves. Similar results have been obtained on C. grandis [8].

Under Mn-toxicity, the majority of $\mathrm{Mn}$ in $C$. sinensis and $C$. grandis plants was retained in the roots (Figure 2E), as previously found for C. grandis [8], lucerne [35] and Douglas fir [38]. However, in rice exposed to Mn-toxicity, $\mathrm{Mn}$ was predominantly accumulated in leaves compared with roots [39]. The tolerance of plants to $\mathrm{Mn}$ is associated not only with low Mn uptake, but also with relatively little $\mathrm{Mn}$ translocation from roots to shoots [40,41]. Our results showed that under Mn-toxicity, C. sinensis plants accumulated more $\mathrm{Mn}$ in roots and less $\mathrm{Mn}$ in shoots than $C$. grandis ones, and that the concentration of Mn was lower in Mn-toxicity C. sinensis leaves than in C. grandis ones (Figure 2). This might contribute to the Mn-tolerance of C. sinensis. We isolated 122 differentially expressed TDFs from Mn-toxicity C. grandis leaves, which belong to different functional categories (Additional file 2 and Figure 7B), meaning that Mn-toxicity affected different physiological and biochemical pathways. In contrast, we only identified 15 differentially expressed TDFs from Mn-toxicity $C$. sinensis leaves (Additional file 3 and Figure 7A). Obviously, the transcript profile was less affected by Mn-toxicity in $C$. sinensis leaves compared to C. grandis ones, which may be 


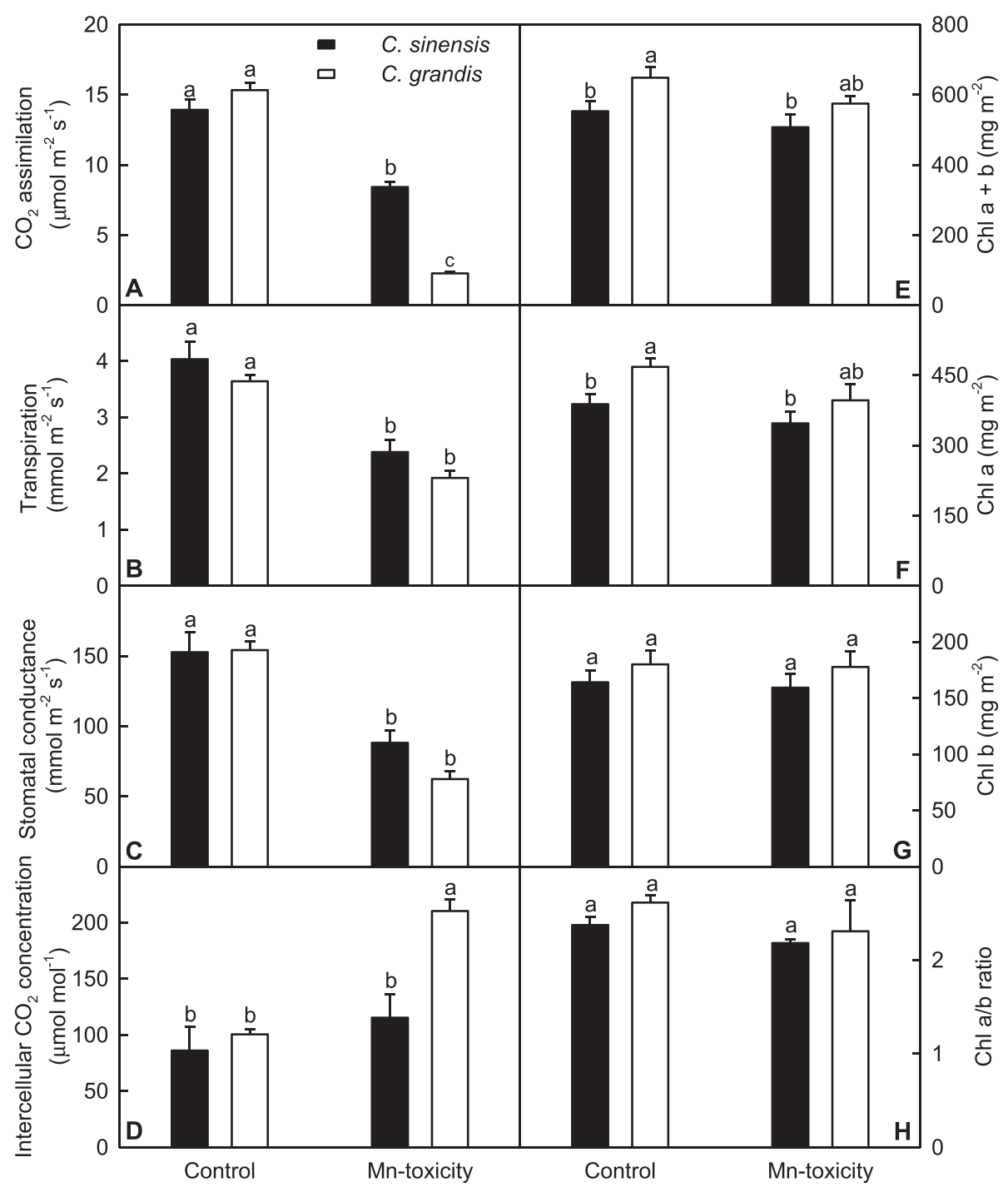

Figure 5 Effects of Mn-toxicity on gas exchange and $\mathrm{Chl}$ of Citrus grandis and C. sinensis leaves. (A-D) Leaf $\mathrm{CO}_{2}$ assimilation, transpiration, stomatal conductance and intercellular $\mathrm{CO}_{2}$ concentration. (E-G) Leaf concentrations of $\mathrm{Chl} \mathrm{a}+\mathrm{b}, \mathrm{Chl}$ a and Chl b. (H) Leaf ratio of Chl a/b. Bars represent means $\pm \operatorname{SE}(n=4$ or 5$)$. Different letters above the bars indicate a significant difference at $P<0.05$.

associated with the less $\mathrm{Mn}$ accumulation in Mn-toxicity C. sinensis leaves (Figure $2 \mathrm{C}$ and $\mathrm{G}$ ). These data also support above inference that $C$. sinensis is more tolerant to Mn-toxicity than C. grandis.

\section{Genes involved in biological regulation and signal transduction}

Protein phosphorylation, a versatile post-translational modification (PTM), is involved in almost all plant signal pathways and plays important roles in regulation of abiotic stress responses [42]. Phosphorylation and dephosphorylation of a protein often serve as an "on-and-off" switch in the regulation of cellular activities. For optimal regulation, kinases and phosphatases must strike a balance in any given cell [43]. As shown in Additional file
2, Mn-toxicity decreased the expression levels of genes involved in phosphorylation [leucine-rich receptor-like protein kinase (TDF \#066-4), probable receptor-like protein kinase (TDF \#104-5), Ser/Thr protein kinase isolog (TDF \#170-1), VH1-interacting kinase (TDF \#199-1), calcium-dependent protein kinase 1-like (TDF \#165-2) and OBP3-responsive gene 1 (TDF \#238-1) genes] and dephosphorylation [protein phosphatase $2 \mathrm{a}$, regulatory subunit, putative (TDF \#044-1)] except for increased expression of a mitogen-activated protein kinase 1 (MAPK 1, TDF \#089-1) gene in C. grandis leaves. This means that the balance between phosphorylation and dephosphorylation was upset and phosphorylation of some proteins might be impaired in Mn-toxicity C. grandis ones. MAPK cascades are important signal modules that 


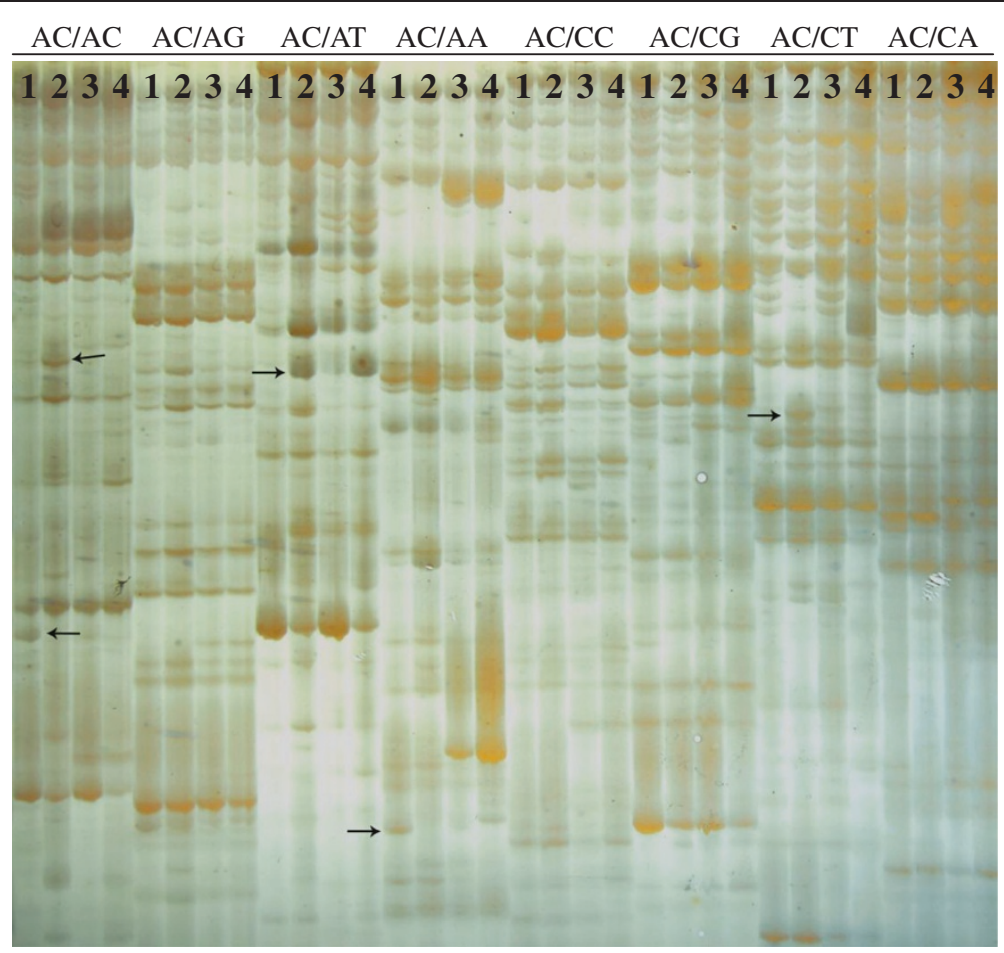

Figure 6 CDNA-AFLP profiles using one EcoR I selective primer and eight Mes I selective primers. One EcoR I selective primer: EcoR I-AC; Eight Mes I selective primers: Mes I-AC, AG, AT, AA, CC, CG, CT and CA; 1: Control leaves of Citrus grandis; 2: Mn-toxicity leaves of C. grandis; 3: Control leaves of $C$. sinensis; 4: Mn-toxicity leaves of C. sinenis; Arrows indicate differentially expressed TDFs.

convert signals generated at the receptors/sensors to appropriate cellular responses [44]. Increasing evidence demonstrates the role of MAPK signal in different heavy metal stresses for different plant species [45]. The observed higher expression level of MAPK 1 (TDF \#0891) in Mn-toxicity leaves agrees with the previous reports that excess copper $(\mathrm{Cu})$, cadmium $(\mathrm{Cd})$ and mercury $(\mathrm{Hg})$ led to the activation of a novel MAPK gene OsMSRMK2 from Japonica-type rice [46], and that MAPK pathways were activated by excess $\mathrm{Cu}$ and $\mathrm{Cd}$ in $M$. sativa seedlings [47]. Thus, MAPK cascade might play a role in the responses of plants to Mn-toxicity. In contrast to C. grandis, VH1-interacting kinase (TDF \#199a) gene in C. sinensis leaves was induced by Mn-toxicity (Additional file 3).

MAPKs are able to phosphorylate different substrates in different cellular compartments, including transcription factors (TFs) in the nucleus [29]. Thus, genes related to TFs might be affected in Mn-toxicity C. grandis leaves due to altered expression level of MAPK 1 (TDF \#089-1) gene (Additional file 2). As expected, Mn-toxicity increased the expression levels of genes encoding TF jumonji domaincontaining protein (TDF \#09-2) and Myb family transcription factor (TDF \#232-1), and decreased the expression levels of genes encoding TF ILR3 (TDF \#105-2), C3H4 type zinc finger protein (TDF \#156-2), putative TF (TDF $\# 045-2)$ and DNA-binding storekeeper protein-related transcriptional regulator (TDF \#131-1) in C. grandis leaves (Additional file 2). Jumonji C (jmjC) domain-containing proteins have been shown to function as demethylases and to involve in chromatin structure and gene expression [48]. Recently, Govind et al. [49] showed that two Jumonji TFs (Jumonji like TF and TF jumonji domain-containing protein) and other genes (Lea5, HSP20 and HSP70) were induced in drought-stressed peanut (Arachis hypogaea) plants, which agrees with our results that Mn-toxicity C. grandis leaves had higher mRNA levels of gene encoding TF jumonji domain-containing protein (TDF \#09-2, Additional file 2). They also found that silencing of Jumonji (JMJC) made the transgenic tobacco (Nicotiana benthamiana) plants more tolerant to drought, while down-regulation of HSP7O resulted in susceptibility [49]. Rampey et al. [50] reported that ilr3-1 Arabidopsis seedlings were less sensitive than wild type to Mn-toxicity. ILR3 is a basic helix-loop-helix type TF, which seems to regulate metal homeostasis in part through the action of putative $\mathrm{Fe} / \mathrm{Mn}$ CCC1-like (VIT1-like) transporters. Therefore, the down-regulation of ILR3 in Mn-toxicity C. grandis leaves might be an adaptive response. Like $C$. grandis, the expression of DNA-binding storekeeper protein-related 


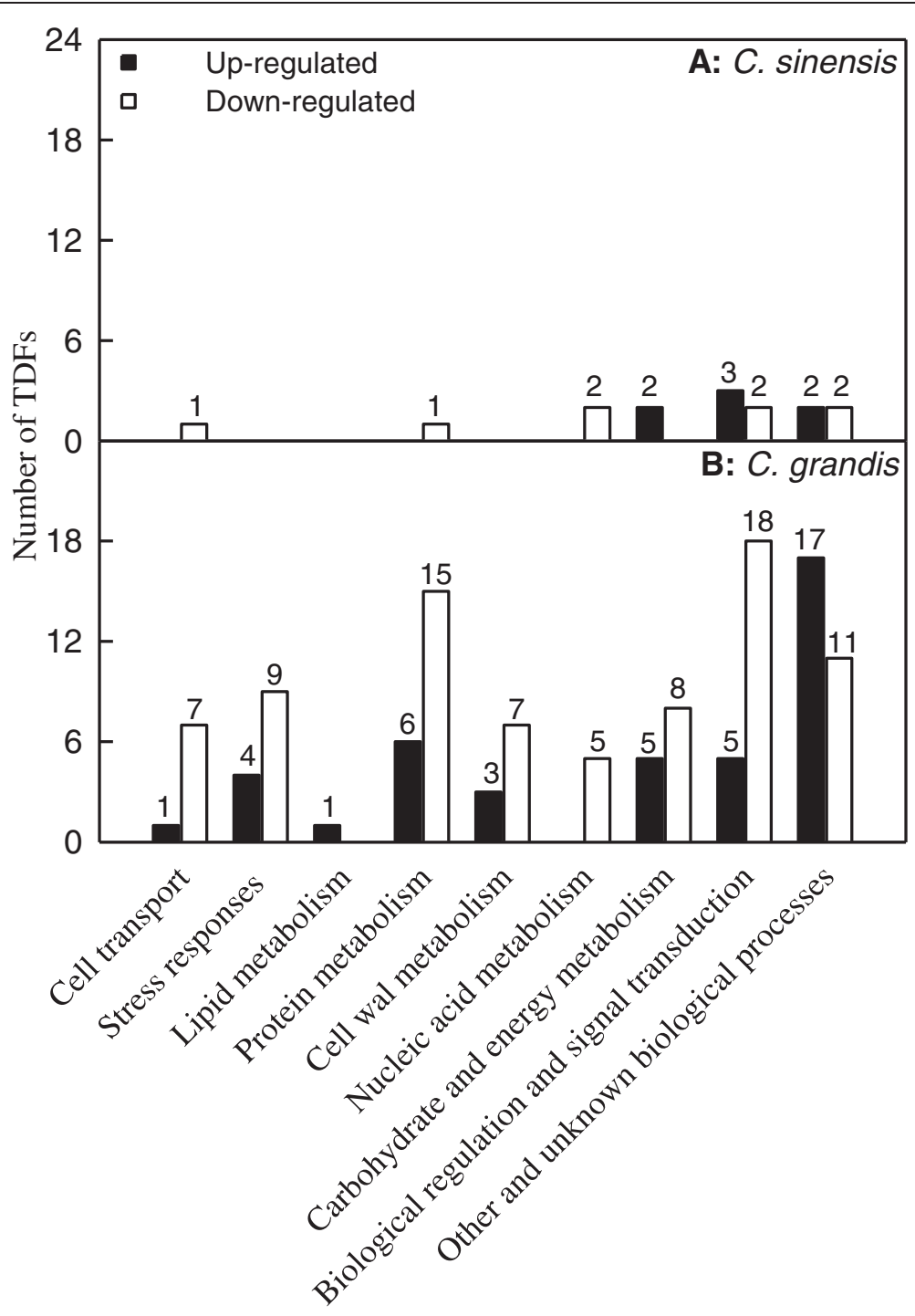

Figure 7 Differentially expressed genes in Mn-toxicity citrus leaves as compared with control ones.

transcriptional regulator (TDF \#131a) was inhibited in $C$. sinensis leaves. ILR3 (TDF \#105b), however, was upregulated in Mn-toxicity C. sinensis leaves (Additional file 3).

Calcium $(\mathrm{Ca})$ is a secondary messenger and has been suggested to participate in heavy metal signal [29]. Indeed, $\mathrm{Ca}$ concentration in runner bean (Phaseolus coccineus) cells greatly increased in response to Cd stress [51]. Ca may interact with calmodulin to propagate the signal and ultimately to regulate downstream genes involved in heavy metal transport, metabolism, and tolerance [52]. In this study, Mn-toxicity decreased the expression levels of Ca-dependent protein kinase 1-like (TDF \#165-2), calmodulin-binding transcription activator 5 (TDF\# 102) and $\mathrm{Ca}^{2+}$-binding protein (TDF \#186-2) genes in C. grandis leaves, and increased the expression levels of Ca-binding EF-hand domain-containing protein (TDF \#153-3) gene in C. grandis leaves and calmodulin-binding transcription activator 5 (TDF \#100b) in C. sinensis ones (Additional file 2 and Additional file 3). Thus, genes related to $\mathrm{Ca}^{2+}$ signal might be involved in response to Mn-toxicity. Busov et al. [53] characterized a 5NG4 gene from juvenile loblolly pine shoots, which was highly and specifically induced by auxin prior to adventitious root formation. Toxicity of $\mathrm{Mn}$, on the other hand, led to auxin deficiency caused by activation of indole-acetic acid oxidase under excess Mn [20]. This supports our data that auxin-induced protein 5NG4 gene (TDF \#233a) was down-regulated in C. sinensis leaves (Additional file 3). Similarly, the transcript abundance of auxin-response factor (TDF \#111-2) in C. grandis leaves 


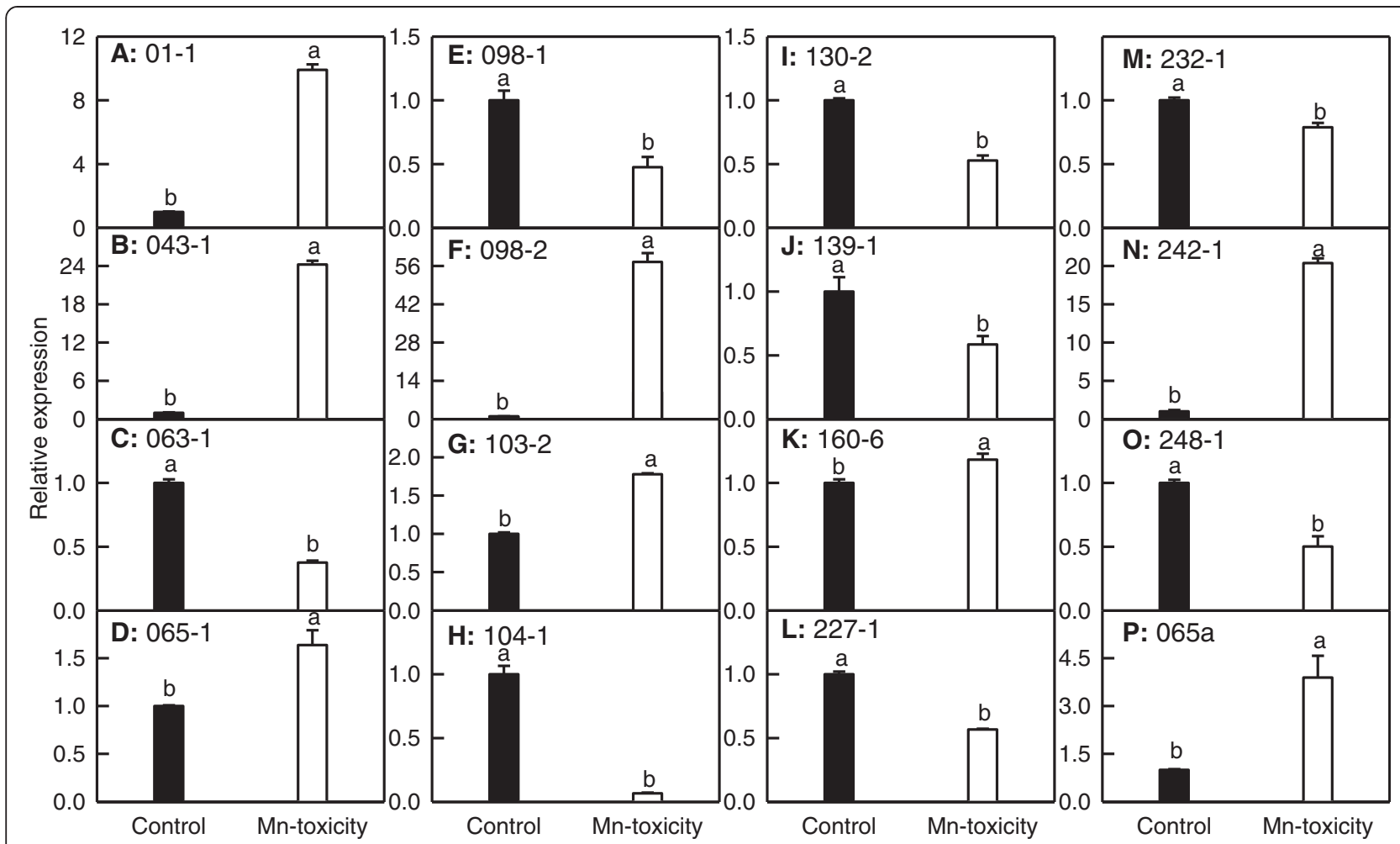

Figure 8 Relative expression of TDFs from Citrus grandis (A-O) and from C. sinensis (P) leaves. Relative expression of genes encoding ATP synthase subunit alpha (TDF \#01-1; A), glycoside hydrolase family 28 protein (TDF \#043-1; B), anthranilate phosphoribosyltransferase-like protein (TDF \#063-1; C), ATP synthase subunit alpha (Atp 1; TDF \#065-1; D), monodehydroascorbate reductase (TDF \#098-1; E), xylem cysteine proteinase 2 (TDF \#098-2; F), catalase (TDF \#103-2; G), peroxidase 42 (TDF \#104-1; H), NADP-dependent alkenal double bond reductase P2 (TDF \#130-2; I), DNA polymerase phi subunit (TDF \#139-1; J), regulator of Vps4 activity in the MVB pathway protein (TDF \#160-6; K), glutathione S-transferase Tau2 (TDF \#227-1; L), Myb family transcription factor (TDF \#232-1; M), cell wall-associated hydrolase (TDF \#242-1; N), ABC transporter family protein (TDF \#248-1; O) in C. grandis leaves and Atp1 (TDF \#065a; P) in C. sinensis leaves. Bars represent means \pm SE $(n=3)$. Different letters above the bars indicate a significant difference at $P<0.05$.

also decreased in response to Mn toxicity (Additional file 2). However, Mn-toxicity increased 5NG4 mRNA level in C. grandis ones (TDF \#233-1, Additional file 2).

Transducin/WD-40 repeat-containing protein is a G protein involved in a wide range of functions that include signal transduction, transcription and stress-tolerant function. It was up-regulated by excess $\mathrm{Cu}$ in germinating rice seeds [54,55], but was down-regulated by Mn-toxicity in $C$. grandis leaves (TDF \#085-3, Additional file 2).

VQ motif-containing proteins play important roles in plant growth, development and defense responses. Lossof function mutants and/or overexpression lines for the VQ genes are altered in seed size, tolerance to abiotic stress, or resistance to pathogen infection [56,57]. Liu et al. [56] reported that transgenic Arabidopsis plants overexpressing the AtARVQ1, a gene encoding a plant-specific VQ motif-containing protein, were more resistant to arsenate stress. Recently, Cheng et al. [58] showed that plant VQ motif-containing proteins played critical roles in the network of WRKY-mediated gene expression. We found that under Mn-toxicity, the expression level of VQ genes (TDF \#061-2) was decreased in C. grandis, which is in agreement with the previous report that AtARVQ1 expression was strongly down-regulated by arsenate stress [56].

Zhang et al. [59] observed that A. thaliana Fes1A could prevent cytosolic HSP70 degradation. Thus, the observed lower mRNA level of HSP70 nucleotide exchange factor fes1 (TDF \#235-2, Additional file 2) in Mn-toxicity C. grandis leaves agrees with the results that the expression levels of HSP70 (TDF \#237-6) and stromal $70 \mathrm{kDa}$ heat shock-related protein, chloroplastic-like gene (TDF $\# 156-1)$ in C. grandis ones decreased in response to Mntoxicity (Additional file 2). Similar result has been obtained on B-deficient C. sinensis roots [60].

Phosphatidylinositol (PtdIns) 4-kinase catalyzes the phosphorylation of PtdIns in the D-4 position of the inositol ring. This is the committed step in the synthetic pathway leading to PtdIns 4,5-bisphosphate (PtdIns 4,5$\mathrm{P}_{2}$ ). Apart from this function in signal transduction, both 
PtdIns 4-P and PtdIns 4,5- $\mathrm{P}_{2}$ appear to have other cellular functions (such as regulating cytoskeletal architecture, acting as enzyme effectors, or acting as components of vesicular fusion [61]. We found that the expression level of PtdIns 4-kinase type 2-beta (TDF \#099-2) in C. grandis leaves decreased in response to Mn-toxicity (Additional file 2), which disagrees with Mn-stimulated PtdIns 4kinase from Dunaliella parva [62].

Based on these results above mentioned, we conclude that the responses of citrus plants to Mn-toxicity might be regulated in multiple signal pathways.

\section{Genes involved in carbohydrate and energy metabolism}

Thirteen genes in C. grandis leaves and two genes in $C$. sinensis ones related to carbohydrate and energy metabolism were altered under Mn-toxicity (Additional file 2 and Additional file 3, Figure 7). ATP synthase is an important enzyme that provides energy for the cell to use through the synthesis of ATP. Hamilton et al. [63] showed that exposure of wheat to $\mathrm{Al}$ increased mitochondrial $\mathrm{F}_{1} \mathrm{~F}_{0}$-ATPase activity only in the Al-tolerant wheat variety, and concluded that the Al-induced increase in ATP synthase activity was an adaptive response involved in $\mathrm{Al}$ tolerance. Similar to Al-toxicity, Mn-toxicity increased the expression levels of synthase subunit alpha (Atp 1) in C. grandis (TDF \#065-1) and C. sinensis (TDF \#65a) leaves and ATP synthase subunit alpha (TDF \#01-1) in C. grandis leaves (Additional file 2 and Additional file 3). Aconitate hydrolyase (AH) involved in glycolysis catalyses the interconversion of citrate and isocitrate, via a cisaconitate. Our finding that the expression of AH 2 (TDF \#116-1, Additional file 2) was induced in Mn-toxicity $C$. grandis leaves means that its activity was enhanced by Mn-toxicity, which is in agreement with the previous report that $\mathrm{AH}$ was up-regulated by $\mathrm{Cd}$ stress [64]. In addition, Mn-toxicity also increased the expression levels of NADPH-ferrihemoprotein reductase (TDF \#178-1) and cytochrome (Cyt) c biogenesis orf256 (TDF \#236-1) genes related to respiration in $C$. grandis leaves (Additional file 2). Overall, the metabolic pathways related to ATP synthesis and reducing power production might be activated in $\mathrm{Mn}$-stressed leaves to yield more energy needed to meet the high-energy demand of stressed cell. By contrast, the mRNA level of gene encoding 2-phospho-D-glycerate hydrolase (also known as enolase, TDF \#244-1), an essential and ubiquitous glycolytic enzyme responsible for the catalysis of the conversion of 2-phosphoglycerate (2-PG) to phosphoenolpyruvate (PEP), was down-regulated in Mntoxicity C. grandis leaves (Additional file 2). This agrees with the previous report that the abundance of enolase in Agrostis stolonifera leaves was decreased after $10 \mathrm{~d}$ of heat stress [65]. Ferreira et al. in Populus euphratica leaves observed that the level of enolase was transiently increased after $30 \mathrm{~h}$ of heat stress, followed by a decrease after $54 \mathrm{~h}$ of heat stress [66]. However, other studies showed that leaf enolase was induced in various plants by different abiotic stresses, such as water stress in maize [67], cold stress in tobacco [68], salt stress in ice plant (Mesembryanfhemum crysfallinum) [69] and Cd-stress in Phytolacca americana [70]. Like to enolase, the expression level of gene encoding Cyt P450 (TDF \#197-1), an enzyme typically catalyzing the reaction: $\mathrm{RH}+\mathrm{O}_{2}+\mathrm{NADPH}+\mathrm{H}^{+} \rightarrow \mathrm{ROH}+\mathrm{H}_{2} \mathrm{O}+$ $\mathrm{NADP}^{+}$, was reduced in Mn-toxicity $\mathrm{C}$. grandis leaves (Additional file 2), which might contribute to maintaining NADPH homeostasis by decreasing its utilization. However, the expression of Cyt P450, family 96, subfamily A, polypeptide 9 (TDF \#029a) gene in C. sinsnsis leaves was induced by Mn-toxicity (Additional file 3 ), which is in agreement with the report that at least 5 of the $29 \mathrm{Cyt}$ P450s were induced in Arabidopsis by abiotic and biotic stress including Alternaria brassicicola or Alternaria alternata, paraquat, rose bengal, UV-C stress, heavy metal stress $\left(\mathrm{CuSO}_{4}\right)$, mechanical wounding, drought, high salinity, low temperature or hormones [71]. Transgenic tobacco and potato plants expressing Cyt P450 tolerated better oxidative stress after herbicide treatment [72]. Therefore, the observed higher mRNA level of Cyt P450, family 96, subfamily A, polypeptide 9 might be advantegous to $\mathrm{Mn}$ toxicity tolerance of $C$. sinensis plants.

Thioredoxins (Trxs) are small proteins, which are involved in the cell redox regulation. Trx $m$, a chloroplastic protein, preferentially activates NADP-malate dehydrogenase (NADP-MDH), a key enzyme involved in carbon fixation and sugar biosynthesis during photosynthesis. Historically the m-type Trxs were so named because they were able to activate NADP-MDH [73]. The activity of NADP-MDH might be down-regulated in Mn-toxicity C. grandis leaves due to lower mRNA levels of $\operatorname{Trx} m$ (TDF \#058-2) and Trx $m 4$ (TDF \#085-2) (Additional file 2). Evidence shows that Trx $m 1, m 2$, and $m 4$ could act as antioxidants, i.e. possibly by serving as hydrogen donors for a Trx-dependent peroxidase [74].

Trehalose-6-phosphate synthase (TPS) is a key enzyme for synthesizing trehalose, which plays an important role in abiotic stress tolerance of plants [75]. The observed lower level of TPS (TDF \#013-3) in Mn-xicity C. grandis leaves (Additional file 2) indicates that Mn-toxicity might decrease leaf concentration of trehalose, thus lowering the stress tolerance.

ATP sulfurylase (ATPS) activity were enhanced by sulphur (S) deprivation and reduced after resupply of $\mathrm{SO}_{4}^{2-}$ [76]. Heiss et al. [77] reported that Cd stress strongly increased the expression levels of ATPS and 5'-adenylysulfate reductase in roots and leaves of 6-week-old Brassica juncea, accompanied by enhanced cysteine concentration in roots and leaves, and concluded that roots and leaves responded to $\mathrm{Cd}$ stress with a coordinative up-regulation of several S assimilation enzymes to meet an increased demand for 
cysteine during phytochelatin synthesis. However, the expression of ATPS (TDF \#168-1) was down-regulated in Mn-toxicity C. grandis leaves (Additional file 2).

UDP-glycosyltransferases (UGTs), which glycosylate a broad array of aglycones, including plant hormones, all major classes of plant secondary metabolites, and xenobiotics such as herbicides, play an important role for the stabilization, enhancement of water solubility and detoxification of natural products [78]. Cytokinins can be glucosylated to form $\mathrm{O}$-glucosides and $\mathrm{N}$-glucosides. The glycoconjugates are inactive and are considered to play a role in hormonal homeostasis. Hou et al. [79] showed that UGT76C1 and UGT76C2 (two members of group $\mathrm{H}$ ) recognized all cytokinins and glucosylated them at the $N^{7}$ and $N^{9}$ positions. Veselov et al. [21] reported that $\mathrm{Cd}$ stress sharply lowered the concentration of cytokinin in wheat roots and shoots caused by elevated activity of cytokinin oxidase. Obviously, the down-regulation of UDP-glycosyltransferase 76F1-like (one member of group $\mathrm{H}$, TDF \#185-4) gene in Mn-toxicity C. grandis leaves (Additional file 2) is advantageous to cytokinin homeostasis under Mn-toxicity if leaf concentration of cytokinin decreased in response to Mn-toxicity.

\section{Genes involved in nucleic acid metabolism}

Evidence shows that heavy metals inhibit plant nucleic acid metabolism [80,81]. As expected, the expression levels of genes encoding THO complex, subunit 5 (TDF \#134-2), DNA polymerase phi subunit (TDF \#139-1), histone H4 (TDF \#165-1), DNA (cytosine-5)- methyltransferase DRM 2-like (TDF \#200-1) and luc7-like protein 3-like (TDF \# 200-2) in C. grandis leaves (Additional file 2) and genes encoding THO complex, subunit 5 (TDF \#134b) and histone H4 (TDF \#165a) in C. sinensis ones (Additional file 3) decreased in response to Mn-toxicity, indicating that leaf nucleic acid metabolism might be impaired by Mn-toxicity.

\section{Genes involved in protein metabolism}

Mn-toxicity has been demonstrated to affect protein metabolism in plants [12]. We found that the expression levels of three ribosomal genes encoding ribosomal protein S3 (TDF \#06-1), ribosomal protein S8 (TDF \#097-1) and $60 \mathrm{~S}$ ribosomal protein L2, mitochondrial-like (TDF \# 134-1), which are involved in mature ribosome assembly and translation processes, were down-regulated in Mntoxicity $C$. grandis leaves (Additional file 2), while only one ribosomal gene encoding $60 \mathrm{~S}$ ribosomal protein L2, mito chondrial-like (TDF \#134a) in C. sinensis leaves was downregulated by $\mathrm{Mn}$-toxicity (Additional file 3 ). This indicates that the biosynthesis of protein in Mn-toxicity C. grandis leaves might be impaired more severe than in Mn-toxicity C. sinensis ones, which is in agreement with our data that Mn-toxicity decreased the concentration of total soluble protein in C. grandis leaves, but did not affect its concentration in C. sinensis ones (Figure 4A). However, the expression of 30 S ribosomal protein S13 gene (TDF \#140-1) was induced in Mn-toxicity C. grandis leaves (Additional file 2).

Translational control of protein synthesis depends on numerous eukaryotic initiation factors (eIFs). Our finding that the expression of gene encoding similar to translation initiation factor IF2 (TDF \#011-2) was down-regulated in Mn-toxicity C. grandis leaves (Additional file 2) agrees with our previous report that the abundances of eIF4B1, eIF3 subunit and eIF3G1 in C. sinensis roots decreased in response to B-deficiency [60]. However, salt and heavy metal induced the accumulation of rice eIF5A-1 and eIF5A-2 mRNAs in rice cells [82]. Elongation factors whose expressions have been demonstrated to correlate to the high rate of protein synthesis in developing plant tissues [83] facilitate translational elongation, from the formation of the first peptide bond to the formation of the last one in the ribosome. Guo et al. [84] isolated a translation elongation factor 2-like protein gene from a cold defective Arabidopsis mutant, los 1-1. The los1-1 mutant plants were impaired in protein synthesis under cold stress. We found that the expression level of one gene encoding translation elongation factor-1 alpha, partial (TDF \#181-2) in C. grandis leaves decreased in response to Mn-toxicity (Additional file 2), which agrees with the previous results obtained on drought-stressed soybean nodules [85], anoxia maize roots [86], and B-deficient roots of C. sinensis [60], Brassica napus [87] and Lupinus albus [88]. However, the abundances of chloroplast translational elongation factor $\mathrm{Tu}$ and elongation factor $\mathrm{P}$ in rice leaves increased in response to Cd stress [89]. Thus, it appears that the influence of abiotic stress on translation elongation factors depends on plant species and kinds of stresses. In addition, the expression level of gene encoding tetratricopeptide repeat-containing protein (TDF \#090-1) involved in protein synthesis was down-regulated in $\mathrm{Mn}$ toxicity C. grandis leaves (Additional file 2). These results further demonstrate that protein biosynthesis is impaired in Mn-toxicity C. grandis leaves.

Mn-toxicity increased the expression levels of genes encoding ATP-dependent Clp protease (TDF \#245-1), cysteine proteinase (TDF \#044-2) and xylem cysteine proteinase 2 (TDF \#098-2) in C. grandis leaves (Additional file 2). This indicates that the hydrolysis of some proteins might be up-regulated in Mn-toxicity leaves, thus decreasing leaf concentration of total soluble protein. This is also supported by our data that Mn-toxicity leaves had lower concentration of total soluble protein (Figure 4A). However, the expression levels of genes encoding carboxyl-terminal peptidase (TDF \#104-6), papain family cysteine protease (TDF \#107-1), cathepsin B-like cysteine proteinase like protein (TDF \#233-3) and $\alpha / \beta$-hydrolase-like protein 
(TDF \#221-1) decreased in response to Mn-toxicity (Additional file 2).

Like other PTMS (such as phosphorylation), ubiquitination, which serves as a versatile PTM, plays a key role in regulating plant response to abiotic stresses [90]. The up-regulation of genes encoding MND1-interacting protein 1 (TDF \#148-1) and ubiquitin-conjugating enzyme E2 10 (TDF \#240-1) in Mn-toxicity C. grandis leaves (Additional file 2) might be an adaptive response to $\mathrm{Mn}$ toxicity. However, the expression levels of ubiquitincorrelative genes such as ubiquitin-protein ligase (TDF \# 03-2) and BTB and MATH domain-containing protein (TDF \#138-2) in C. grandis leaves decreased in response to Mn-toxicity (Additional file 2), meaning that the ubiquitination of some proteins might be impaired in Mn-toxicity C. grandis leaves.

Three genes [chorismate synthase (TDF \#247-1), cystathionine $\beta$-synthase (CBS) domain-containing protein (TDF \#216-3) and 2-oxoglutarate (2OG) and Fe(II)-dependent oxygenase-like protein (TDF \#061-3) ] involved in amino acid metabolism was down-regulated in Mn-toxicity $C$. grandis leaves (Additional file 2). This means that the biosynthesis of amino acids might be impaired in Mn-toxicity C. grandis leaves. Chorismate synthase catalyzes the last of the seven steps in the shikimate pathway which is used in prokaryotes, fungi and plants for the biosynthesis of aromatic amino acids [91]. CBS catalyzes the first step of the transsulfuration pathway from homocysteine to cystathionine. Jung et al. [92] observed that CBSX2 directly modulated Trx in chloroplasts, which affected the level of $\mathrm{H}_{2} \mathrm{O}_{2}$ and, consequently, the expression of the genes involved in secondary cell-wall thickening, concluding that CBSX2 protein played a critical role in thickening of the secondary cell walls of the endothecium during anther dehiscence in Arabidopsis. Transgenic tobacco plants overexpressing OsCBSX4 isolated from rice displayed enhanced tolerance to salinity, heavy metal, and oxidative stress [93]. This observed lower expression level of gene encoding CBS domain-containing protein (TDF \#216-3) in C. grandis leaves (Additional file 2) disagrees with our previous data that the abundance of CBS family protein in $C$. sinensis roots increased in response to B-deficiency [60].

\section{Genes involved in lipid metabolism}

Lecithin-cholesterol acyltransferase (LCAT) catalyzes the transacylation of acyl groups from phospholipids to sterols in mammals and yeast. Sterol acylation is an essential process of sterol homeostasis in eukaryotic cells. In Arabidopsis, phospholipid sterol acyltransferase 1 (PSAT1), which displays homology with the mammalian LCAT, catalyzes a phospholipid-dependent (acyl-CoAindependent) formation of sterol esters [94]. Recent work with Arabidopsis showed that sterol ester concentration decreased in leaves of psat1-1 or psat1-2 mutants accompanied by an early leaf senescence phenotype, suggesting a major contribution of the PSAT1 in maintaining both free sterol homeostasis in plant cell membranes and leaf viability during developmental aging [95]. The up-regulation of lecithin-cholesterol acyltransferase-like 1 (TDF \#153-2, Additional file 2) in Mn-toxicity C. grandis leaves might enhance the leaf concentration of sterol ester, thus preventing leaf senescence.

\section{Genes involved in cell wall metabolism}

Our results showed that the expression levels of genes $[\alpha-1,2$-fucosyltransferase (TDF \#037-3), caffeic acid Omethyltransferase (TDF \#080-1), O-fucosyltransferase family protein (TDF \#069-8), cellulose synthase-like protein (TDF \#044-4), protein SAH7 (TDF \#05-1), 4-coumarateCoA ligase 3 (TDF \#151-1) and CBS domain-containing protein (TDF \#216-3)] involved in cell wall biosynthesis were down-regulated in Mn-toxicity C. grandis leaves (Additional file 2). In addition, the mRNA levels of gene encoding glycoside hydrolase family 28 protein (TDF \#0 43-1), which catalyze the hydrolytic cleavage of the pectin and gene encoding cell wall-associated hydrolase (TDF \#2 42-1) were up-regulated in Mn-toxicity C. grandis leaves (Additional file 2). Therefore, the formation of cell wall might be impaired in Mn-toxicity leaves. However, the expression of gene encoding protein trichome birefringencelike 39 (TDF \#158-3) was induced in Mn-toxicity $C$. grandis leaves (Additional file 2).

\section{Genes involved in stress responses}

Mn-toxicity has been demonstrated to stimulate ROS production in plants $[12,14,16]$. Since Mn-toxicity did not affect the concentration of MDA in citrus leaves (Figure 4B), some protective antioxidant enzymes should be up-regulated to meet the increased requirement for scavenging ROS. Our results showed that the expression of gene encoding catalase (CAT, TDF \#103-2), an enzyme involved in scavenging $\mathrm{H}_{2} \mathrm{O}_{2}$, was induced in Mn-toxicity C. grandis leaves (Additional file 2), which agrees with the previous report that Mn-toxicity C. grandis leaves had increased specific activity of CAT and similar leaf area-based activity of CAT [8]. Besides ROS scavenger enzymes, this detoxification mechanism also involves "house-keeping" enzymes. The family of Nudix hydrolases (NUDXs), which catalyze the hydrolytic breakdown of nucleoside diphosphates linked to some other moieties such as a phosphate, sugar or nucleoside, are one of these "house-keeping" enzyme families [96]. Ogawa et al. [97] showed that AtNUDX19, a chloroplastic AtNUDX, played an important role in modulation of the NADH and/or NADPH pools through the hydrolysis of $\mathrm{NAD}(\mathrm{P}) \mathrm{H}$ to reduced nicotinamide mononucleotide (NMNH) in Arabidopsis chloroplasts. Transgenic Arabidopsis plants overexpressing AtN $U D X 2$ and $A t N U D X 7$ displayed enhanced tolerance to 
oxidative stress, resulting from the maintenance of $\mathrm{NAD}^{+}$ and ATP levels by nucleotide recycling of free ADP-ribose molecules [98]. The higher expression level of NUDX19 (TDF \#160-1) in C. grandis leaves (Additional file 2) agrees with the previous reports that the abundance of NUDX homolog 3 in C. sinensis roots increased in response to Bdeficiency [60] and Chrysanthemum lavandulifolium ClNUDX1, ClNUDX3, ClNUDX7 and ClNUDX8 were induced by salt, drought, heat, and cold stresses [99]. However, the expression levels of genes encoding monodehydroascorbate reductase (MDAR, TDF \#098-1), peroxidase 42 (TDF \#104-1), glutathione S-transferase (GST) Tau2 (TDF \#227-1), NADP-dependent alkenal double bond reductase P2 (TDF \#130-2), Trx $m$ (TDF \#058-2), TRx $m 4$, chloroplastic-like (TDF \#085-2), and CBS domain-con taining protein (TDF \#216-3) related to oxidative defense in C. grandis leaves decreased in response to $\mathrm{Mn}$-toxicity (Additional file 2). It is noteworthy that Mn-toxicity $C$. grandis leaves had higher specific activity of MDAR and leaf area-based activity of MDAR compared with controls [8]. The discrepancy between the expression level of $M D A R$ and the activity of the corresponding enzyme indicates that PTMs might affect MDAR activity.

Senescence is a genetically programmed decline in various cellular processes and involves in the hydrolysis of macromolecules such as proteins and lipids. It is governed by the developmental age and is induced or enhanced by biotic and abiotic stresses. Generally in plants the term senescence and programmed cell death (PCD) denote the processes that initiate the programmed death of individual cell. The senescence can be considered as one of the examples for PCD. As expected, the expression level of one gene encoding for putative senescence-associated protein (TDF \#164-4) was up-regulated by Mn-toxicity in the less Mn-tolerant C. grandis leaves (Additional file 2). This agrees with the previous report that the gene was highly differentially expressed only in the heat-sensitive fescue (Festuca sp.) genotype at $44^{\circ} \mathrm{C}$ [100]. In addition, the expression levels of apoptosis linked genes [xylem cysteine proteinase 2 (TDF \#098-2), cysteine proteinase (TDF \# 044-2) and ALG2-interacting protein X (TDF \#054-1) genes] were enhanced in Mn-toxicity $C$. grandis leaves (Additional file 2). Thus, it is reasonable to assume that the Mn-toxicity sensitive C. grandis plants were under great stress and leaf senescence was accelerated, which might contribute to plant survival by using more metabolites through glycolysis, and protein and lipid degradation. As shown in Figure 9, the Mn-toxicity-induced senescence in C. grandis leaves was a very complicated process.

HSPs/chaperones have been demonstrated to play a key role in protecting plants against heavy metal stress [64]. The observed lower expression levels of genes encoding heat shock protein-related, partial (TDF \#158-2), heat shock protein 60-3A (TDF \#160-5), HSP70 (TDF \#237-6) and stromal $70 \mathrm{kDa}$ heat shock-related protein, chloroplas tic-likes (TDF \#156-1) in Mn-toxicity C. grandis leaves (Additional file 2) indicate decreased protein synthesis in these leaves, as indicated by decreased leaf concentration of total soluble proteins (Figure 4A). This is similar to the previous report that the abundance of HSP70 was enhanced in leaves of high $\mathrm{Cd}$-accumulating soybean cultivar, but was lowered in low Cd-accumulating one [101].

One crucial adaptive mechanism of plants to P-deficiency is the immediate cleavage of phosphate $(\mathrm{Pi})$ from phosphorylated substrates. Phosphoethanolamine/phosphocholine phosphatase (PPsPase) may release Pi from organic to maintain Pi homeostasis of plant cells [102]. The downregulation of PPsPase, putative gene (TDF \#198-1) in $C$. grandis leaves (Additional file 2) might decrease the release of Pi from phosphorylated substrates, thus lowering leaf $\mathrm{P}$ concentration (Figure 3A). This agrees with the previous report that Mn-toxicity decreased $\mathrm{P}$ concentration in tea leaves [17].

\section{Genes involved in cell transport}

Eight genes in C. grandis leaves and one gene in C. sinensis ones were regulated by Mn-toxicity (Additional file 2 and Additional file 3, Figure 7). We found that the expression of citrus sucrose transporter 1 (TDF \#073-1, Additional file 2) was induced in Mn-toxicity C. grandis leaves, which is in agreement with the previous report that the gene strongly expressed in source, sugar exporting organs [103], because Mn-toxicity increased or did not affect the concentrations of non-structural carbohydrates in C. grandis leaves [8]. The up-regulation of citrus sucrose transporter 1 might be helpful to decrease sugar accumulation in Mn-toxicity leaves, which might in turn lead to feedback suppression of $\mathrm{CO}_{2}$ assimilation [104].

One of strategies of plants to deal with heavy metals is to transport them out of the cells, thereby removing them from the cytosol. Kim et al. [105] observed that transgenic A. thaliana plants overexpressing the $\mathrm{ABC}$ transporter AtPDR8 were more resistant to $\mathrm{Cd}$ or lead $(\mathrm{Pb})$ and displayed lower $\mathrm{Cd}$ concentration in roots and shoots than wild-type plants, while AtPDR 8 RNAi transgenic plants and T-DNA insertion lines were more sensitive to $\mathrm{Cd}$ or $\mathrm{Pb}$ and had higher $\mathrm{Cd}$ concentration, concluding that the $\mathrm{ABC}$ transporter AtPDR8 is a Cd extrusion pump conferring heavy metal resistance. The down-regulation of genes encoding ABC-transporter-like protein (TDF \#208-1) and ABC transporter family protein (TDF \#248-1) in $C$. grandis leaves (Additional file 2) indicates that the extrusion of $\mathrm{Mn}$ from leaves might be lessened in response to Mn-toxicity, which might be one of the causes that Mntoxicity C. grandis leaves accumulated more $\mathrm{Mn}$ than $C$. sinensis ones (Figure 2G).

Evidence has shown that CorA-like proteins may represent the major transport systems in eukaryotes such as 


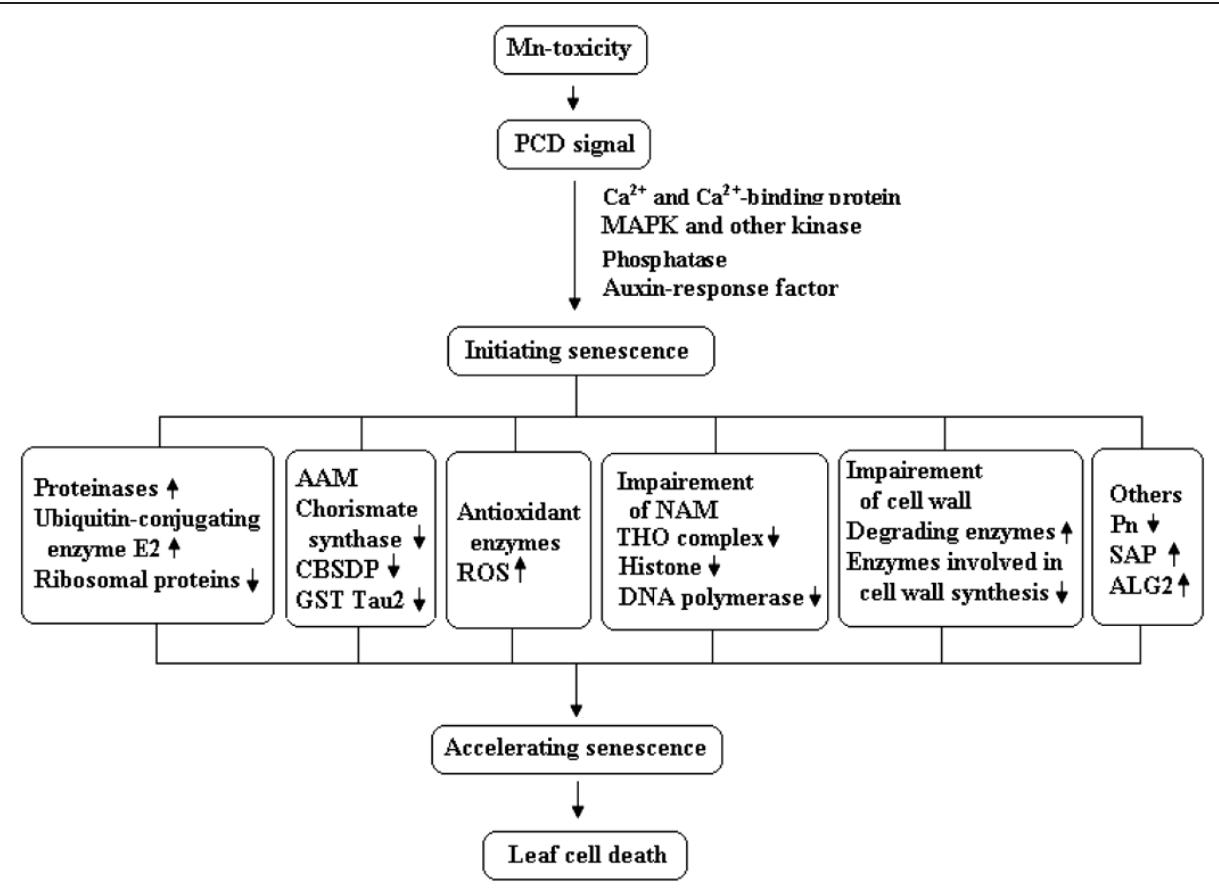

Figure 9 The potential regulatory network of Mn-toxicity-induced senescene in Citrus grandis leaves. AAM: Amino acid metabolism; ALG2: Apoptosis linked gene 2 (ALG2)-interacting protein X; CBSDP: Cystathionine $\beta$-synthase (CBS) domain-containing protein; GST: Glutathione S-transferase; MAPK: mitogen-activated protein kinase; NAM: Nucleic acid metabolism; PCD: Programmed cell death; Pn: Photosynthesis; ROS: Reactive oxygen; SAP: Senescence-associated protein; $\uparrow$ : Up-regulation; $\downarrow$ : Down-regulation.

yeast, animals, and plants [106,107]. The down-regulation of $\mathrm{Mg}$ transporter CorA-like protein gene in Mn-toxicity $C$. grandis (TDF \#234-2, Additional file 2) and C. sinensis (TDF \#234b, Additional file 3) leaves might reduce Mg transport, hence decreasing leaf $\mathrm{Mg}$ concentration. This agrees with the previous report that Mn-toxicity decreased leaf concentration of $\mathrm{Mg}$ [17]. Interestingly, Mg concentration was decreased by Mn-toxicity only in C. grandis leaves, but was not significantly affected in $C$. sinensis leaves (Figure 3B). This means that leaf $\mathrm{Mg}$ concentration is also regulated by other factors.

Plant cyclic nucleotide gated channels (CNGCs), which comprise a large gene family in Arabidopsis, have been proposed to be involved in multiple plant physiological processes including plant growth and heavy metal toxicity tolerance [108]. Evidence suggests that CNGCs paly a role in heavy metal homeostasis, for example, in tobacco, overexpression of tobacco CNGC (NtCBP4) led to hypersensitivity to $\mathrm{Pb}$ [109]. However, Sunkar et al. [110] showed that transgenic tobacco plants overexpressing a truncated NtCBP4 exhibited improved tolerance to $\mathrm{Pb}^{2+}$ and decreased uptake of this metal ion. We found that the expression of cyclic nucleotide gated channel 9 gene (TDF \# 216-2) was down-regulated in Mn-toxicity C. grandis leaves (Additional file 2), suggesting that the gene might be involved in the response to Mn-toxicity.
Our results showed that the expression of gene encoding protease inhibitor/seed storage/lipid transfer protein (LTP) family protein (TDF \#242-2) was down-regulated in Mn-toxicity C. grandis leaves (Additional file 2), indicating that the exchange of lipids between membranes might be decreased.

\section{Conclusions}

Our results clearly demonstrated that $C$. sinensis was more tolerant to Mn-toxicity than C. grandis. Under Mn-toxicity, $C$. sinensis plants accumulated more $\mathrm{Mn}$ in roots and less $\mathrm{Mn}$ in shoots (leaves) than C. grandis ones, and that the leaf concentration of $\mathrm{Mn}$ was lower in the former. This might contribute to the Mn-tolerance of C. sinensis. In this study, we first used the cDNAAFLP technique to compare the mRNA levels of genes from control and Mn-toxicity leaves of two citrus species differing in Mn-tolerance. In Mn-toxicity C. grandis leaves, 42 up-regulated and 80 down-regulated genes were isolated, while only seven up-regulated and eight down-regulated genes were identified in Mn-toxicity $C$. sinensis ones. Obviously, Mn-toxicity affected gene expression far less in C. sinensis leaves than in C. grandis ones, which might be associated with less leaf Mn concentration in Mn-toxicity C. grandis leaves. cDNA-AFLP analysis suggests that the responses of $C$. grandis leaves 
to Mn-toxicity might include following several aspects: (1) accelerating leaf senescence; (2) activating the metabolic pathway related to ATPase synthesis and reducing power production; (3) decreasing cell transport; (4) inhibiting protein and nucleic acid metabolisms; (5) impairing the formation of cell wall; and (6) triggering multiple signal transduction pathways. We also identified many new Mn-toxicity-responsive genes involved in biological and signal transduction (i.e. VH1-interacting kinase, OBP3-responsive gene 1, transcription factor IL), carbohydrate metabolism (i.e. NADPH-ferrihemoprotein reductase, trehalose-6-phosphate synthase), protein metabolism (i.e. MND1-interacting protein 1, chorismate synthase), stress responses (i. e. Nudix hydrolase 19, ALG2-interacting protein X) and cell transport (i.e. cyclic nucleotide gated channel 9). Further studies will elucidate the roles of these genes in response to $\mathrm{Mn}$ toxicity, which will help me to design Mn-tolerant transgenic crops.

\section{Methods}

\section{Plant culture, Mn treatments and sampling}

The study was conducted from April to December, 2012 at Fujian Agriculture and Forestry University (FAFU). Plant culture, Mn treatments, and sampling were performed according to $\mathrm{Li}$ et al. [8]. Briefly, 6-week-old seedlings of 'Xuegan' (Citrus sinensis) and 'Sour pummelo' (Citrus grandis) were transplanted to $6 \mathrm{~L}$ pots containing sand. Seedlings, two per pot, were grown in a greenhouse under natural photoperiod at FAFU. Each pot was supplied with $500 \mathrm{~mL}$ of nutrient solution every two day. The nutrient solution contained the following macronutrients (in $\mathrm{mM}$ ): $\mathrm{KNO}_{3}, 1.25 ; \mathrm{Ca}\left(\mathrm{NO}_{3}\right)_{2}, 1 ;\left(\mathrm{NH}_{4}\right)$ $\mathrm{H}_{2} \mathrm{PO}_{4}, 0.25 ; \mathrm{MgSO}_{4}, 0.5$; and micronutrients (in $\mu \mathrm{M}$ ): $\mathrm{H}_{3} \mathrm{BO}_{3}, 10 ; \mathrm{ZnCl}_{2}, 2 ; \mathrm{CuSO}_{4}, 0.5 ;\left(\mathrm{NH}_{4}\right)_{6} \mathrm{Mo}_{7} \mathrm{O}_{24}, 0.065$; $\mathrm{MnSO}_{4}$, 2; Fe-EDTA, 20. Eight weeks after transplanting, each pot was supplied every other day until dripping with nutrient solution (approximately $500 \mathrm{~mL}$ ) containing $2 \mu \mathrm{M}$ (control) or $600 \mu \mathrm{M}$ (Mn-toxicity) $\mathrm{MnSO}_{4}$ for 17 weeks. At the end of the experiment, fully expanded leaves from different replicates and treatments were used for all the measurements. Leaves were collected at noon under full sun and immediately frozen in liquid nitrogen and were stored at $-80^{\circ} \mathrm{C}$ until extraction.

\section{Measurements of root and shoot DW and determination of $\mathrm{Mn}, \mathrm{Mg}$ and $\mathrm{P}$}

Ten plants per treatment from different pots were harvested and divided into their parts (roots, and shoots). The plant parts were then dried at $70^{\circ} \mathrm{C}$ for $48 \mathrm{~h}$ and the $\mathrm{DW}$ mesured.

Root, stem and leaf Mn concentration and leaf Mg concentration were assayed by inductively coupled plasma (ICP) emission spectrometry after microwave digestion with $\mathrm{HNO}_{3}$ [111]. Leaf $\mathrm{P}$ concentration was measured according to Ames [112]. There were four replicates per treatment (one leaf per replicate, one leaf per plant).

\section{Determination of Chl, total soluble protein and MDA in leaves}

Leaf $\mathrm{Chl} \mathrm{a}+\mathrm{b}, \mathrm{Chl} \mathrm{a}$ and $\mathrm{Chl} \mathrm{b}$ were assayed according to Lichtenthaler [113]. Briefly, 2 frozen leaf discs $\left(0.608 \mathrm{~cm}^{2}\right.$ in size) were extracted with $8 \mathrm{~mL}$ of $80 \%(\mathrm{v} / \mathrm{v})$ acetone for $24 \mathrm{~h}$ in the dark. The extracts were determined using Libra S22 ultraviolet-visible spectrophotometer (Biochrom Ltd., Cambridge, UK). Leaf total soluble protein was extracted with $50 \mathrm{mM} \mathrm{Na}_{2} \mathrm{HPO}_{4}-\mathrm{KH}_{2} \mathrm{PO}_{4}(\mathrm{pH} \mathrm{7.0})$ and $5 \%$ (w/v) insoluble polyvinylpolypyrrolidone (PVPP), and determined according to Bradford [114] using bovine serum albumin (BSA) as standard. Extraction and determination of leaf MDA was performed according to Hodges et al. [115]. There were four replicates per treatment (one leaf per replicate, one leaf per plant).

\section{Leaf gas exchange measurements}

Measurements were made with a CIARS-2 portable photosynthesis system (PP systems, Herts, UK) at ambient $\mathrm{CO}_{2}$ concentration under a controlled light intensity of $1000 \mu \mathrm{mol} \mathrm{m} \mathrm{m}^{-2} \mathrm{~s}^{-1}$ between 9:30 and 10:30 on a clear day. During measurements, leaf temperature and vapor pressure deficit (VPD) were $26.9 \pm 1.1^{\circ} \mathrm{C}$ and $2.0 \pm 0.1 \mathrm{kPa}$, respectively. There were five replicates per treatment (one leaf per replicate, one leaf per plant).

\section{RNA preparation and cDNA synthesis}

Total RNA was extracted from 200-300 mg of the frozen leaves using Recalcirtant Plant Total RNA Extraction Kit (Centrifugal column type, Bioteke Corporation, China) according to manufacturer's instructions. The integrity and quantity of total RNA was detected by $1 \%$ (w/v) agarose gel electrophoresis and spectrophotometer at $260 \mathrm{~nm}$. First-strand cDNA was synthesized from 2 $\mu \mathrm{g}$ of total RNA using RevertAid ${ }^{\mathrm{TM}}$ First Strand cDNA Synthesis Kit (Thermo Scientific, Massachusetts, USA). Second cDNA strand was performed with Escherichia coli RNase H, E. coli DNA Ploymerase I and T4 DNA Polymerase (TaKaRa, China), and stoped with $0.25 \mathrm{M}$ EDTA (pH 8.0) and 10\% sodium dodecyl sulfate (SDS). The resulting double-stranded cDNA was purified using equal volume of phenol : chloroform : isoamyl alcohol (25: $24: 1)$. Five $\mu \mathrm{L}$ was checked using agarose gel electrophoresis in order to observe an expected smear between $100 \mathrm{bp}$ and $1000 \mathrm{bp}$.

\section{cDNA-AFLP analysis}

The cDNA-AFLP-based transcript profiling procedure was performed as described by Cao et al. [116] with some modifications. Double-stranded cDNA (600 ng) was digested 
with restriction enzymes: $5 \mathrm{U}$ each of $E c o \mathrm{R}$ I (Thermo Scientific, Massachusetts, USA; $3 \mathrm{~h}$ at $37^{\circ} \mathrm{C}$ ) and Mse I (Tru $1 \mathrm{I}$, Thermo Scientific, Massachusetts, USA; $3 \mathrm{~h}$ at $65^{\circ} \mathrm{C}$ ). The resulting restricted fragments were ligated to adaptors $(E c o R$ I, $0.2 \mu \mathrm{M}$ forward primer: 5'- CTCGTAGACTG CGTACC-3' and reverse primer: 3'- CATCTGACGCAT GGTTAAP -5; Mse I, $2 \mu \mathrm{M}$ forward primer: 5'-GACG ATGAGTCCTGAG-3' and reverse primer: 3'-TACTCAG GACTCATP-5') with T4-DNA ligase (Thermo Scientific, Massachusetts, USA) for $10-16 \mathrm{~h}$ at $16^{\circ} \mathrm{C}$. Prior to ligation, the two adaptors were heated at $94^{\circ} \mathrm{C}$ for $3 \mathrm{~min}$, followed by $65^{\circ} \mathrm{C}$ for $10 \mathrm{~min}, 37^{\circ} \mathrm{C}$ for $10 \mathrm{~min}$ and $25^{\circ} \mathrm{C}$ for $10 \mathrm{~min}$. The resulting ligated products were pre-amplified with the corresponding preamplification premiers: EcoR I, 5'-GA CTGCGATCCAATTC-3' and Mse I, 5'-GATGAGTCCT GAGTAA-3'. From a 100-fold dilution of the pre-amplified samples, a $5 \mu \mathrm{L}$ diluted sample was used for the selective amplification using 256 combinations of the following primers: 16 derivatives of EcoR I primers 5'-GACTGC GATCCAATTCEE-3' and 16 derivatives of Mse I primers 5'-GATGAGTCCTGAGTAAMM-3'; where EE and MM represent AA, AT, AC, AG, TA, TC, TT, TG, CA, CT, CG, CC, GA, GC, GT and GG. The selective amplification products were separated on a $6 \%(\mathrm{w} / \mathrm{v})$ polyacrylamide gel run at $50 \mathrm{~W}$ for $2.5 \mathrm{~h}$. The gels were silver stained as described by Bassam et al. [117] to visualize the cDNA bands. Samples for cDNA-AFLP analysis were run in two replicates at least.

The TDFs of interests were selected based on their presence, absence or differential intensity and cut out with a scalpel, and incubated in $50 \mu \mathrm{L}$ of dd $\mathrm{H}_{2} \mathrm{O}$ for $30 \mathrm{~min}$ in a boiling water bath, then centrifuged at 10000 revolutions per min at room temperature (Eppendorf 5418R, Hamburg, Germany). The supernatant was stored at $-20^{\circ} \mathrm{C}$ for re-amplification. The eluted DNA was reamplified by PCR using the same primer combinations. The re-amplified products representing the Mn-toxicityresponsive TDFs were checked on 1\% (w/v) agarose gels, each band is isolated and eluted using DNA Agarose Gel Recovery Kit (Solarbio, China). Before being sequenced by BGI Technology Corporation (Shenzhen, China), these TDFs fragments were ligated to pGEM-T EASY vector according to usage information of $\mathrm{pGEM}^{\circledR}$-T Easy Vector System I (Promega, USA), then transduced into E. coli (DH5 $\alpha$ ) competent cells using Ampicillin as the selecting agent. All sequences were input into the VecScreen (http:// www.ncbi.nlm.nih.gov/tools/vecscreen/) to identify and remove all of the vector sequence. Homology of TDFs' sequences was analyzed using the BLASTX and BLASTN searching engines (http://blast.ncbi.nlm.nih.gov/Blast.cgi). Their functional categories were assigned based on the analysis of information reported for each sequence by The Gene Ontology (http://www.geneontology.org/) and Uniprot (http://www.uniprot.org/).

\section{Quantitative RT-PCR (qRT-PCR) analysis}

Total RNA was isolated from the frozen leaves of control and Mn-excess plants by TRIzol reagent (Invitrogen, Carlsbad, CA, USA). About $2.0 \mu \mathrm{g}$ total RNA was used for first-strand cDNA synthesis using the RevertAid ${ }^{m}$ First-Strand cDNA Synthesis Kit (Thermo Scientific, Massachusetts, USA) following the manufacturer's instructions. The resulting cDNA was diluted to $100 \mu \mathrm{L}$ using Tris-EDTA buffer (10 mM Tris, $50 \mathrm{mM} \mathrm{NaCl}$, 1 mM EDTA, pH 7.8). Specific primers were designed from the sequences of 15 singleton TDFs using Primer Primier Version 5.0 (PREMIER Biosoft International, CA, USA). The sequences of the $F$ and $R$ primers used are given in Additional file 4. qRT-PCR was performed using a $\mathrm{SYBR}^{\circledR}$ Premix Ex TaqTM (Tli RNaseH Plus, Takara Bio, Inc, Otsu, Shiga, Japan) with the Step One Plus Real-Time System (Applied Biosystems, California, USA) in an Eco Real-Time PCR System (Illumina, USA ). The cycling conditions were $30 \mathrm{~s}$ at $95^{\circ} \mathrm{C}$, followed by 40 cycles of $95^{\circ} \mathrm{C}$ for $5 \mathrm{~s}, 60^{\circ} \mathrm{C}$ for $15 \mathrm{~s}$. Samples for qRT-PCR were run in 3 biological replicates with 3 technical replicates. Relative gene expression was calculated using ddCt algorithm. For the normalization of gene expression, citrus actin (GU911361.1) gene was used as an internal standard and the leaves from control plants were used as reference sample, which was set to 1 .

\section{Experimental design and statistical analysis}

There were 20 pots ( 40 seedlings) per treatment in a completely randomized design. Experiments were performed with 2-10 replicates. Results represented the mean \pm SE. Statistical analyses of data were carried out by ANOVA tests. Means were separated by the least significant difference (LSD) test at $P<0.05$ level.

\section{Additional files}

Additional file 1: Manganese (Mn)-toxicity symptoms on leaves of Citrus grandis and C. sinensis. A: Control leaves of C. grandis; B: Mntoxicity leaves of $C$. grandis; $C$ : Control leaves of $C$. sinensis; D: Mn-toxicity leaves of $C$. sinenis.

Additional file 2: Homology of differentially expressed CDNA-AFLP fragments with known gene sequences in database using BLASTN algorithm along their expression patterns in Mn-toxicity leaves of Citrus grandis.

Additional file 3: Homology of differentially expressed CDNA-AFLP fragments with known gene sequences in database using BLASTN algorithm along their expression patterns in Mn-toxicity leaves of Citrus sinensis.

Additional file 4: Specific primer pairs used for qRT-PCR expression analysis.

Competing interests

The authors declare that they have no competing interests. 


\section{Authors' contributions}

CPZ carried out most of the experiments and drafted the manuscript. YPQ participated in the design of the study. $X Y$ participated in the sequence alignment. LTY participated in the design of the study and coordination. PG performed the statistical analysis. XXZ carried out the measurement of $\mathrm{Mn}$ and ChI. FJK carried out the cultivation of seedlings. LSC designed and directed the study and revised the manuscript. All authors have read and approved the final manuscript.

\section{Acknowledgement}

This study was financially supported by the earmarked fund for China Agriculture Research System.

\section{Author details}

${ }^{1}$ Institute of Horticultural Plant Physiology, Biochemistry and Molecular Biology, Fujian Agriculture and Forestry University, 350002 Fuzhou, China. ${ }^{2}$ College of Horticulture, Fujian Agriculture and Forestry University, 350002 Fuzhou, China. ${ }^{3}$ Institute of Materia Medica, Fujian Academy of Medical Sciences, 350001 Fuzhou, China. ${ }^{4}$ College of Life Science, Fujian Agriculture and Forestry University, 350002 Fuzhou, China. ${ }^{5}$ College of Resources and Environmental Sciences, Fujian Agriculture and Forestry University, 350002 Fuzhou, China.

Received: 1 July 2013 Accepted: 11 September 2013

Published: 14 September 2013

\section{References}

1. Armstrong FA: Why did nature choose manganese to make oxygen? Phil Trans R SOC B 2008, 363:1263-1270.

2. Marschner H: Mineral Nutrition of Higher Plants. London: Academic Press; 1995

3. González A, Steffen KL, Lynch JP: Light and excess manganese implications for oxidative stress in common bean. Plant Physiol 1998, 118:493-504.

4. Mukhopadhyay MJ, Sharma A: Manganese in cell metabolism of higher plants. Bot Rev 1991, 57:117-149.

5. Foy CD: Physiological effects of hydrogen, aluminum, and manganese toxicities in acid soils. In Soil Acidity and Liming. 2nd edition. Edited by Adams F. Madison: American Society of Agronomy; 1984:57-97.

6. Michopoulos P, Cresser MS: Effects of simulated acid precipitation on the cycling of manganese under stika spruce (Picea sitchensis). Biogeochemistry 2002, 61:323-325.

7. Kitao M, Lei TT, Koike T: Effects of manganese toxicity on photosynthesis of white birch (Betula platyphylla var. japonica) seedlings. Physiol Plant 1997, 101:249-256.

8. Li Q, Chen LS, Jiang HX, Tang N, Yang LT, Lin ZH, Yang GH: Effects of manganese-excess on $\mathrm{CO}_{2}$ assimilation, ribulose-1, 5-bisphosphate carboxylase/oxygenase, carbohydrates and photosynthetic electron transport of leaves, and antioxidant systems of leaves and roots in Citrus grandis seedlings. BMC Plant Biol 2010, 10:42.

9. Millaleo R, Reyes-Díaz M, Alberdi M, Ivanov AG, Krol M, Hüner NPA: Excess manganese differentially inhibits photosystem I versus II in Arabidopsis thaliana. J Exp Bot 2013, 64:343-354.

10. Fecht-Christoffers MM, Braun HP, Lemaitre-Guillier C, VanDorsselaer A, Horst WJ: Effect of manganese toxicity on the proteome of the leaf apoplast in cowpea. Plant Physiol 2003, 133:1935-1946.

11. Dučić TD, Polle A: Transport and detoxification of manganese and copper in plants. Braz J Plant Physiol 2005, 17:103-112.

12. Demirevska-Kepova K, Simova-Stoilova L, Stoyanova Z, Holzer R, Feller U: Biochemical changes in barley plants after excessive supply of copper and manganese. Environ Exp Bot 2004, 52:253-266.

13. Führs H, Behrens C, Gallien S, Heintz D, Van Dorsselaer A, Braun HP, Horst WJ: Physiological and proteomic characterization of manganese sensitivity and tolerance in rice (Oryza sativa) in comparison with barley (Hordeum vulgare). Ann Bot 2010, 105:1129-1140.

14. Gangwar S, Singh VP, Prasad SM, Maurya JN: Modulation of manganese toxicity in Pisum sativum L. seedlings by kinetin. Sci Hort 2010, 126:467-474.

15. Shi Q, Zhu Z, Xu M, Qian Q, Yu J: Effect of excess manganese on the antioxidant system in Cucumis sativus L. under two light intensities. Environ Exp Bot 2006, 58:197-205.
16. Maksimović JD, Mojović M, Maksimović V, Römheld V, Nikolic M: Silicon ameliorates manganese toxicity in cucumber by decreasing hydroxyl radical accumulation in the leaf apoplast. J Exp Bot 2012, 63:2411-2420.

17. Venkatesan S, Hemalatha KV, Jayaganesh S: Characterization of manganese toxicity and its influence on nutrient uptake, antioxidant enzymes and biochemical parameters in tea. Res J Phytochem 2007, 1:52-60.

18. Yao Y, Xu G, Mou D, Wang J, Ma J: Subcellular Mn compartation, anatomic and biochemical changes of two grape varieties in response to excess manganese. Chemosphere 2012, 89:150-157.

19. Papadakis IE, Giannakoula A, Therios IN, Bosabalidis AM, Moustakas M Nastou A: Mn-induced changes in leaf structure and chloroplast ultrastructure of Citrus volkameriana (L.) plants. J Plant Physiol 2007, 164:100-103.

20. Srivastava AK, Singh S: Biochemical markers and nutrient constraints diagnosis in citrus: a perspective. J Plant Nutr 2006, 29:827-855.

21. Veselov D, Kudoyarova G, Symonyan M, Veselov S: Effect of cadmium on ion uptake, transpiration and cytokinin content in wheat seedlings. Bulg J Plant Physiol 2003, 29:353-359.

22. Bowler C, Slooten L, Vandenbranden S, De Rycke R, Botterman J, Sybesma C, van Montagu M, Inze D: Manganese superoxide dismutase can reduce cellular damage mediated by oxygen radicals in transgenic plants. EMBO J 1991, 10:723-1732.

23. Woo EJ, Dunwell JM, Goodenough PW, Marvier AC, Pickersgill RW: Germin is a manganese containing homohexamer with oxalate oxidase and superoxide dismutase activities. Nat Struct Biol 2000, 7:1036-1040.

24. Zeng W, Chatterjee M, Faik A: UDP-xylose-stimulated glucuronyltransferase activity in wheat microsomal membranes: characterization and role in glucurono (arabino) xylan biosynthesis. Plant Physiol 2008, 147:78-91.

25. LeClere S, Tellez R, Rampey RA, Matsuda SPT, Bartel B: Characterization of a family of IAA-amino acid conjugate hydrolases from Arabidopsis. J Biol Chem 2002, 277:20446-20452.

26. Durst F: The correlation of phenylalanine ammonia-lyase and cinnamic acid hydroxylase activity changes in Jerusalem artichoke tuber tissues. Planta 1976, 132:221-227.

27. Chen ZH, Walker RP, Acheson RM, Leegood RC: Phosphoenolpyruvate carboxykinase assayed at physiological concentrations of metal ions has a high affinity for $\mathrm{CO}_{2}$. Plant Physiol 2002, 128:160-164.

28. Führs H, Specht A, Erban A, Kopka J, Horst WJ: Functional associations between the metabolome and manganese tolerance in Vigna unguiculata. J Exp Bot 2012, 63:329-340.

29. DalCorso G, Farinati S, Furini A: Regulatory networks of cadmium stress in plants. Plant Signal Behav 2010, 5:663-667.

30. Craciun AR, Courbot M, Bourgis F, Salis P, Saumitou-Laprade P, Verbruggen N: Comparative CDNA-AFLP analysis of Cd-tolerant and -sensitive genotypes derived from crosses between the $\mathrm{Cd}$ hyperaccumulator Arabidopsis halleri and Arabidopsis lyrata ssp. petraea. J Exp Bot 2006, 57:2967-2983.

31. Fusco N, Micheletto L, DalCorso G, Borgato L, Furini A: Identification of cadmium-regulated genes by cDNA-AFLP in the heavy metal accumulator Brassica juncea L. J Exp Bot 2005, 56:3017-3027.

32. Bachem CWB, Hoeven RS, Bruijn SM, Vreugdenhil D, Zabeau M, Visser RGF: Visualization of differential gene expression using a novel method of RNA fingerprinting based on AFLP: analysis of gene expression during potato tuber development. Plant J 1996, 9:745-753.

33. Ditt RF, Nester EW, Comai L: Plant gene expression response to Agrobacterium tumefaciens. Proc Natl Acad Sci U S A 2001, 98:10954-10959.

34. Mills HA, Jones JB Jr: Plant Analysis Handbook II. Georgia: MicroMacro Publishing; 1996.

35. Gherardi MJ, Rengel Z: Genotypes of lucerne (Medicago sativa L.) show differential tolerance to manganese deficiency and toxicity when grown in bauxite residue sand. Plant Soil 2003, 249:287-296.

36. Lidon FC, Barreiro MG, Ramalho JC: Manganese accumulation in rice: implications for photosynthetic functioning. J Plant Physiol 2004, 161:1235-1244.

37. Nable RO, Houtz RL, Cheniae GM: Early inhibition of photosynthesis during development of Mn toxicity in tobacco. Plant Physiol 1988, 86:1136-1142

38. Dučić TD, Leinemann L, Finkeldey R, Polle A: Uptake and translocation of manganese in seedlings of two varieties of Douglas fir (Pseudotsuga menziesii var. viridis and glauca). New Phytol 2006, 170:11-20. 
39. Lidon F: Tolerance of rice to excess manganese in the early stages of vegetative growth. Characterization of manganese accumulation. J Plant Physiol 2001, 158:1341-1348

40. Mora ML, Rosas A, Ribera A, Rengel Z: Differential tolerance to Mn toxicity in perennial ryegrass genotypes: involvement of antioxidative enzymes and root exudation of carboxylates. Plant Soil 2009, 320:79-89.

41. Vose PB, Randall PJ: Resistance to aluminum and manganese toxicities in plants related to variety and cation exchange capacity. Nature 1962 196:85-86.

42. Mazzucotellin E, Mastrangelo AM, Crosatti C, Guerra D, Stanca AM, Cattivelli $\mathrm{L}$ : Abiotic stress response in plants: when post-transcriptional and posttranslational regulations control transcription. Plant Sci 2008,

174:420-431.

43. Luan S: Protein phosphatase in plants. Annu Rev Plant Biol 2003, 54:63-92.

44. Kim CY, Liu Y, Thorne ET, Yang H, Fukushige H, Gassmann W, Hildebrand D, Sharp RE, Zhang S: Activation of a stress-responsive mitogen-activated protein kinase cascade induces the biosynthesis of ethylene in plants. Plant Cell 2003, 15:2707-2718.

45. Opdenakker K, Remans T, Vangronsveld J, Cuypers A: Mitogen-activated protein (MAP) kinases in plant metal stress: regulation and responses in comparison to other biotic and abiotic stresses. Int J Mol Sci 2012, 13:7828-7853

46. Agrawal GK, Rakwal $\mathrm{R}$, Iwahashi $\mathrm{H}$ : Isolation of novel rice (Oryza sativa $\mathrm{L}$.) multiple stress responsive MAP kinase gene, OsMSRMK2, whose mRNA accumulates rapidly in response to environmental cues. Biochem Biophys Res Commun 2002, 294:1009-1016.

47. Jonak $\mathrm{C}$, Nakagami $\mathrm{H}$, Hirt $\mathrm{H}$ : Heavy metal stress. Activation of distinct mitogen-activated protein kinase pathways by copper and cadmium. Plant Physiol 2004, 136:3276-3283.

48. Chen Z, Zang J, Whetstine J, Hong X, Davrazou F, Kutateladze TG, Simpson M, Mao Q, Pan CH, Dai S, Hagman J, Hansen K, Shi Y, Zhang G: Structural insights into histone demethylation by JMJD2 family members. Cell 2006, 125:691-702.

49. Govind G, Vokkaliga H, Gowda T, Kalaiarasi PJ, Iyer DR, Muthappa SK, Nese S, Makarla UK: Identification and functional validation of a unique set of drought induced genes preferentially expressed in response to gradual water stress in peanut. Mol Genet Genomics 2009, 281:591-605.

50. Rampey RA, Woodward AW, Hobbs BN, Tierney MP, Lahner B, Salt DE, Bartel B: An Arabidopsis basic helix-loop-helix leucine zipper protein modulates metal homeostasis and auxin conjugate responsiveness. Genetics 2006, 174:1841-1857.

51. Skórzyńska-Polit E, Tukendorf A, Selstam E, Baszyński T: Calcium modifies Cd effect on runner bean plants. Environ Exp Bot 1998, 40:275-286.

52. Yang T, Poovaiah BW: Calcium/calmodulin-mediated signal network in plants. Trends Plant Sci 2003, 8:505-512.

53. Busov VB, Johannes E, Whetten RW, Sederoff RR, Spiker SL, Lanz-Garcia C, Goldfarb B: An auxin-inducible gene from loblolly pine (Pinus taeda L.) is differentially expressed in mature and juvenile-phase shoots and encodes a putative transmembrane protein. Planta 2004, 218:916-927.

54. Ahsan N, Lee DG, Lee SH, Kang KY, Lee JJ, Kim PJ, Yoon HS, Kim JS, Lee BH: Excess copper induced physiological and proteomic changes in germinating rice seeds. Chemosphere 2007, 67:1182-1193.

55. Mishra AK, Puranik S, Bahadur RP, Prasad M: The DNA-binding activity of an AP2 protein is involved in transcriptional regulation of a stressresponsive gene, SiWD40, in foxtail millet. Genomics 2012, 100:252-263.

56. Liu AN, Teng Y, Xu WZ, Ma M: AtARVQ1 encodes a novel VQ motifcontaining protein involved in arsenate stress response regulation in Arabidopsis. Chin Sci Bull 2011, 56:1891-1898.

57. Wang A, Garcia D, Zhang H, Feng K, Chaudhury A, Berger F, Peacock WJ, Dennis ES, Luo M: The VQ motif protein IKU1 regulates endosperm growth and seed size in Arabidopsis. Plant J 2010, 63:670-679.

58. Cheng Y, Zhou Y, Yang Y, Chi YJ, Zhou J, Chen JY, Wang F, Fan B, Shi K, Zhou YH, Yu JQ, Chen Z: Structural and functional analysis of VQ motifcontaining proteins in Arabidopsis as interacting proteins of WRKY transcription factors. Plant Physiol 2012, 159:810-825.

59. Zhang JX, Wang C, Yang CY, Wang JY, Chen L, Bao XM, Zhao YX, Zhang H, Liu J: The role of Arabidopsis AtFes1A in cytosolic Hsp70 stability and abiotic stress tolerance. Plant J 2010, 62:539-548.

60. Yang LT, Qi YP, Lu YB, Guo P, Sang W, Feng H, Zhang HX, Chen LS: iTRAQ protein profile analysis of Citrus sinensis roots in response to long-term borondeficiency. J Proteomics. http://dx.doi.org/10.1016/j.jprot.2013.04.025 (on line).
61. Westergren T, Ekblad L, Jergil B, Sommarin M: Phosphatidylinositol 4kinase associated with spinach plasma membranes. Isolation and characterization of two distinct forms. Plant Physiol 1999, 121:507-516.

62. Steinert $P$, Wissing JB, Wagner KG: Manganese-stimulated phosphatidylinositol 4-kinase from Dunaliella parva: purification and characterization. Plant Sci 1994, 101:105-114.

63. Hamilton CA, Good AG, Taylor GJ: Induction of vacuolar ATPase and mitochondrial ATP synthase by aluminum in an aluminum-resistant cultivar of wheat. Plant Physiol 2001, 125:2068-2077.

64. Hossain Z, Komatsu S: Contribution of proteomic studies towards understanding plant heavy metal stress response. Front Plant Sci 2013, 3:310.

65. Xu Y, Gianfagna T, Huang B: Proteomic changes associated with expression of a gene (ipt) controlling cytokinin synthesis for improving heat tolerance in a perennial grass species. J Exp Bot 2010, 61:3273-3289

66. Ferreira S, Hjernø K, Larsen M, Wingsle G, Larsen P, Fey S, Roepstorff P, Salomé Pais M: Proteome profiling of Populus euphratica Oliv. upon heat stress. Ann Bot 2006, 98:361-377.

67. Riccardi F, Gazeau P, de Vienne D, Zivy M: Protein changes in response to progressive water deficit in maize. Quantitative variation and polypeptide identification. Plant Physiol 1998, 117:1253-1263.

68. Jin $Y$, Z Zhang $C$, Yang $H$, Yang $Y$, Huang $C$, Tian $Y$, Lu X: Proteomic analysis of cold stress responses in tobacco seedlings. Afr J Biotech 2011, 10:18991-19004.

69. Forsthoefel NR, Cushman MA, Cushman JC: Posttranscriptional and posttranslational control of enolase expression in the facultative crassulacean acid metabolism plant Mesembryanthemum crystallinum $\mathrm{L}$. Plant Physiol 1995, 108:1185-1195.

70. Zhao L, Sun YL, Cui SX, Chen M, Yang HM, Liu HM, Chai TY, Huang F: Cdinduced changes in leaf proteome of the hyperaccumulator plant Phytolacca americana. Chemospher 2011, 85:56-66.

71. Narusaka Y, Narusaka M, Seki M, Umezawa T, Ishida J, Nakajima M, Enju M, Shinozaki K: Crosstalk in the responses to abiotic and biotic stresses in Arabidopsis: analysis of gene expression in cytochrome P450 gene superfamily by cDNA microarray. Plant Mol Biol 2004, 55:327-342.

72. Gorinova N, Nedkovska M, Atanassov A: Cytochrome P450 monooxygenases as a tool for metabolization herbicides in plants. Biotechnol Biotechnol Eq 2005, 19:105-115.

73. Bassham JA, Krause GH: Free energy changes and metabolic regulation in steady-state photosynthetic carbon reduction. Biochim Biophys Acta 1969, 189:207-221.

74. Collin V, Issakidis-Bourguet E, Marchand C, Hirasawa M, Lancelin JM, Knaff DB, Miginiac-Maslow M: The Arabidopsis plastidial thioredoxins: new functions and new insights into specificity. J Biol Chem 2003, 278:23747-23752.

75. Yuan L, Xiao Y, Christopher AM: Plant cohesins, common themes and unique roles. Curr Protein Pept Sci 2011, 12:93-104.

76. Lappartient GA, Vidmar JJ, Leustek T, Glass ADM, Touraine B: Inter-organ signaling in plants: regulation of ATP sulfurylase and sulfate transporter genes expression in roots mediated by phloem-translocated compound. Plant J 1999, 18:89-95.

77. Heiss S, Schäfer HJ, Haag-Kerwer A, Rausch T: Cloning sulfur assimilation genes of Brassica juncea L.: cadmium differentially affects the expression of a putative low-affinity sulfate transporter and isoforms of ATP sulfurylase and APS reductase. Plant Mol Biol 1999, 39:847-857.

78. Ross J, Li Y, Lim E-K, Bowles DJ: Higher plant glycosyltransferases. Genome Biol 2001, 2:3004.1-3004.6.

79. Hou B, Lim EK, Higgins GS, Bowles DJ: N-glucosylation of cytokinins by glycosyltransferases of Arabidopsis thaliana. J Biol Chem 2004, 279:47822-47832.

80. Cheng S: Effects of heavy metals on plants and resistance mechanisms. Environ Sci Pollut Res 2003, 10:256-264.

81. Gichner T, Patková Z, Száková J, Demnerová K: Toxicity and DNA damage in tobacco and potato plants growing on soil polluted with heavy metals. Ecotox Environ Safe 2006, 65:420-426.

82. Chou WC, Huang YW, Tsay WS, Chiang TY, Huang DD, Huang HJ: Expression of genes encoding the rice translation initiation factor, elF5A, is involved in developmental and environmental responses. Physiol Plant 2004, 121:50-57. 


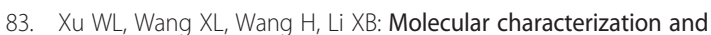
expression analysis of nine cotton GhEF1A genes encoding translation elongation factor 1A. Gene 2007, 389:27-35

84. Guo Y, Xiong L, Ishitani M, Zhu JK: An Arabidopsis mutation in translation elongation factor 2 causes superinduction of CBF/DREB1 transcription factor genes but blocks the induction of their downstream targets under low temperatures. Proc Natl Acad Sci U S A 2002, 99:7786-7791.

85. Gil-Quintana E, Larrainzar E, Seminario A, Díaz-Leal JL, Alamillo JM, Pineda M Arrese-lgor C, Wienkoop S, González EM: Local inhibition of nitrogen fixation and nodule metabolism in drought-stressed soybean. J Exp Bot 2013, 64:2171-2182

86. Chang WWP, Huang L, Shen M, Webster C, Burlingame AL, Roberts JKM: Patterns of protein synthesis and tolerance to anoxia in root tips of maize seedlings acclimated to a low-oxygen environment, and identification of proteins by mass spectrometry. Plant Physiol 2000, 122:295-317.

87. Wang ZH, Wang ZF, Chen SS, Shi L, Xu FS: Proteomics reveals the adaptability mechanism of Brassica napus to short-term boron deprivation. Plant Soil 2011, 347:195-210.

88. Alves M, Moes S, Jenö P, Pinheiro C, Passarinho J, Ricardo CP: The analysis of Lupinus albus root proteome revealed cytoskeleton altered features due to long-term boron deficiency. J Proteomics 2011, 74:1351-1363.

89. Lee K, Bae DW, Kim SH, Han HJ, Liu X, Park HC, Lim CO, Lee SY, Chung WS: Comparative proteomic analysis of the short-term responses of rice roots and leaves to cadmium. J Plant Physiol 2010, 167:161-168.

90. Lyzenga WJ, Stone SL: Abiotic stress tolerance mediated by protein ubiquitination. J Exp Bot 2012, 63:599-616.

91. Macheroux P, Schmid J, Amrhein N, Schaller A: A unique reaction in a common pathway: mechanism and function of chorismate synthase in the shikimate pathway. Planta 1999, 207:325-334

92. Jung KW, Kim YY, Yoo KS, OK SH, Cui MH, Jeong BC, Yoo SD, Jeung JU, Shin JS: A cystathionine- $\beta$-synthase domain-containing protein, $C B S X 2$, regulates endothecial secondary cell wall thickening in anther development. Plant Cell Physiol 2012, 54:195-208.

93. Singh AK, Kumar R, Pareek A, Sopory SK, Singla-Pareek SL: Overexpression of rice CBS domain containing protein improves salinity, oxidative, and heavy metal tolerance in transgenic tobacco. Mol Biotechnol 2012, 52:205-216.

94. Banas A, Carlsson AS, Huang B, Lenman M, Banas W, Lee M, Noiriel A, Benveniste P, Schaller H, Bouvier-Navé P, Stymne S: Cellular sterol ester synthesis in plants is performed by an enzyme (phospholipid: sterol acyltransferase) different from the yeast and mammalian acyl-CoA:sterol acyltransferase. J Biol Chem 2005, 280:34626-34634.

95. Bouvier-Navé P, Berna A, Noiriel A, Compagnon V, Carlsson AS, Banas A, Stymne S, Schaller H: Involvement of the phospholipid sterol acyltransferase 1 in plant sterol homeostasis and leaf senescence. Plant Physiol 2010, 152:107-119.

96. Jambunhathan N, Mahalingam R: Analysis of Arabidopsis growth factor gene 1 (GGF1) encoding a nudix hydrolase during oxidative signaling Planta 2006, 224:1-11.

97. Ogawa T, Yoshimura K, Miyake H, Ishikawa K, Ito D, Tanabe N, Shigeru Shigeoka S: Molecular characterization of organelle-type Nudix hydrolases in Arabidopsis. Plant Physiol 2008, 148:1412-1424.

98. Ogawa T, Ishikawa K, Harada K, Fukusaki E, Yoshimura K, Shigeoka S: Overexpression of an ADP-ribose pyrophosphatase, AtNUDX2, confers enhanced tolerance to oxidative stress in Arabidopsis plants. Plant J 2009, 57:289-301.

99. Huang $\mathrm{H}, \mathrm{CaO} H, \mathrm{Niu}$ Y, Dai S: Expression analysis of Nudix hydrolase genes in Chrysanthemum lavandulifolium. Plant Mol Biol Rep 2012, 30:973-982.

100. Zhang Y, Mian MAR, Chekhovskiy K, So S, Kupfer D, Lai H, Roe BA: Differential gene expression in Festuca under heat stress conditions. J Exp Bot 2005, 56:897-907

101. Hossain Z, Hajika M, Komatsu S: Comparative proteome analysis of high and low cadmium accumulating soybeans under cadmium stress. Amino Acids 2012, 43:2393-2416.

102. May A, Berger S, Hertel T, Köck M: The Arabidopsis thaliana phosphate starvation responsive gene AtPPsPase1 encodes a novel type of inorganic pyrophosphatase. Biochim Biophys Acta 1810, 2011:178-185.

103. Li YC, Shi JX, Weiss D, Goldschmidt EE: Sugars regulate sucrose transporter gene expression in citrus. Biochem Biophys Res Commun 2003, 306:402-407.

104. Stitt M, von Schaewen A, Willmitzer L: "Sink" regulation of photosynthetic metabolism in transgenic tobacco plants expressing yeast invertase in their cell wall involves a decrease of the Calvin-cycle enzymes and an increase of glycolytic enzymes. Planta 1991, 183:40-50.

105. Kim DY, Bovet $L$, Maeshima M, Martinoia E, Lee $Y$ : The $A B C$ transporter AtPDR8 is a cadmium extrusion pump conferring heavy metal resistance. Plant J 2007, 50:207-218.

106. Deng W, Luo K, Li D, Zheng XL, Wei XY, Smith W, Thammina C, Lu LT, Li Y, Pei Y: Overexpression of an Arabidopsis magnesium transport gene, AtMGT1, in Nicotiana benthamiana confers Al tolerance. J Exp Bot 2006, 57:4235-4243

107. Warren MA, Kucharski LM, Veenstra A, Shi L, Grulich PF, Maguire ME: The CorA $\mathrm{Mg}^{2+}$ transporter is a homotetramer. J Bacteriol 2004, 186:4605-4612.

108. Ma W, Smigel A, Verma R, Berkowitz GA: Cyclic nucleotide gated channels and related signaling components in plant innate immunity. Plant Signal Behav 2009, 4:277-282.

109. Arazi T, Sunkar R, Kaplan B, Fromm H: A tobacco plasma membrane calmodulin-binding transporter confers $\mathrm{Ni}^{2+}$ tolerance and $\mathrm{Pb}^{2+}$ hypersensitivity in transgenic plants. Plant J 1999, 20:171-182.

110. Sunkar R, Kaplan B, Bouche N, Arazi T, Dolev D, Talke I, Maathuis FJM, Sanders D, Bouchez D, Fromm H: Expression of a truncated tobacco NtCBP4 channel in transgenic plants and disruption of the homologous Arabidopsis CNGC1 gene confer $\mathrm{Pb}^{2+}$ tolerance. Plant J 2000, 24:533-542.

111. Wang J, Nakazato T, Kinya Sakanishi K, Yamada O, Tao H, Saito I: Single-step microwave digestion with $\mathrm{HNO}_{3}$ alone for determination of trace elements in coal by ICP spectrometry. Talanta 2006, 68:1584-1590.

112. Ames BN: Assay of inorganic phosphate, total phosphate and phosphatase. Methods Enzymol 1966, 8:115-118.

113. Lichtenthaler HK: Chlorophylls and carotenoids: pigments of photosynthetic biomembranes. Methods Enzymol 1987, 148:350-382.

114. Bradford MM: A rapid and sensitive method for quantitation of microgram quantities of protein utilizing the principle of protein-dye binding. Anal Biochem 1976, 72:248-254.

115. Hodges DM, DeLong JM, Forney CF, Prange RK: Improving the thiobarbituric acid-reactive-substances assay for estimating lipid peroxidation in plant tissues containing anthocyanin and other interfering compounds. Planta 1999, 207:604-611.

116. Cao YY, Zhang Q, Chen YH, Zhao H, Lang YZ, Yu CM, Yang JC: Identification of differential expression genes in leaves of rice (Oryza sativa L.) in response to heat stress by CDNA-AFLP analysis. BioMed Res Int 2013, 2013:576189.

117. Bassam BJ, Caetano-Anolles G, Gresshoff PM: Fast and sensitive silver staining of DNA in polyacrylamide gels. Anal Boichem 1991, 196:80-83.

doi:10.1186/1471-2164-14-621

Cite this article as: Zhou et al.: Leaf CDNA-AFLP analysis of two citrus species differing in manganese tolerance in response to long-term manganese-toxicity. BMC Genomics 2013 14:621.

\section{Submit your next manuscript to BioMed Central and take full advantage of:}

- Convenient online submission

- Thorough peer review

- No space constraints or color figure charges

- Immediate publication on acceptance

- Inclusion in PubMed, CAS, Scopus and Google Scholar

- Research which is freely available for redistribution 